\title{
Real-World Emissions from Modern Heavy-Duty Diesel, Natural Gas, and Hybrid Diesel Trucks Operating Along Major California Freight Corridors
}

\author{
David C. Quiros ${ }^{1}$ - Arvind Thiruvengadam ${ }^{2} \cdot$ Saroj Pradhan $^{2} \cdot$ Marc Besch $^{2}$ • \\ Pragalath Thiruvengadam $^{2}$ - Berk Demirgok ${ }^{2}$ - Daniel Carder ${ }^{2} \cdot$ Adewale Oshinuga $^{3}$. \\ Tao Huai ${ }^{1}$. Shaohua $\mathrm{Hu}^{1}$
}

Received: 22 April 2016 / Accepted: 29 June 2016 /Published online: 19 July 2016

(C) Springer International Publishing Switzerland 2016

\begin{abstract}
Emissions were measured from seven heavy-duty (HD) on-road vehicles that were operated along six common route types used for freight transport in California. All vehicles had engines that were certified to the $0.01 \mathrm{~g} / \mathrm{bhp}-\mathrm{h}$ particulate matter (PM) and either a $0.2,0.3$, or $2.3 \mathrm{~g} / \mathrm{bhp}-\mathrm{h}$ nitrogen oxide (NOx) standard. Diesel vehicles had low carbon monoxide (CO) and total hydrocarbon (THC) emissions below brake-specific standards, with route averages ranging from 0.24 to $3.35 \mathrm{~g} \mathrm{CO} /$ $\mathrm{mi}$ and from 0.02 to $0.45 \mathrm{~g} \mathrm{THC} / \mathrm{mi}$. Diesel vehicles equipped with selective catalytic reduction (SCR) had route average NOx emissions ranging from 0.58 to $3.99 \mathrm{~g} / \mathrm{mi}$ ( 0.16 to $0.96 \mathrm{~g} / \mathrm{bhp}-\mathrm{h}$ ). NOx emissions were less route-dependent for the one vehicle with a 12-L compressed natural gas $(\mathrm{CNG})$ engine and threeway catalyst (TWC), with route averages ranging from 0.16 to $0.46 \mathrm{~g} / \mathrm{mi}(0.06$ to $0.13 \mathrm{~g} / \mathrm{bhp}-\mathrm{h})$. The ranking of certification NOx emissions for the seven engines reported during enginedynamometer-based certification was not maintained during real-world testing; for example, highway driving NOx emissions were lower than certification values for some engine families and higher than certification values for others. Route-average gravimetric particulate matter (PM) emissions ranged from 4 to $12 \mathrm{mg} /$ mi, which on a brake-specific basis were at least two times below
\end{abstract}

David C. Quiros

dquiros@arb.ca.gov

Berk Demirgok

bedemirgok@mail.wvu.edu

1 Monitoring and Laboratory Division, California Air Resources Board, 1927 13th, Sacramento, CA 95811, USA

2 Mechanical and Aerospace Department, West Virginia University, 395 Evansdale Drive, Morgantown, WV 26506, USA

3 South Coast Air Quality Management District, 21865 Copley Drive, Diamond Bar, CA 91765, USA the $0.01 \mathrm{~g} / \mathrm{bhp}-\mathrm{h}$ standard. Ion speciation of PM emissions indicated that the most prevalent species were sulfate $\left(\mathrm{SO}_{4}{ }^{2-}\right)$ for the model year (MY) 2007 diesel vehicle equipped with a diesel particulate filter (DPF) and no SCR, nitrate $\left(\mathrm{NO}_{3}{ }^{-}\right)$for conventional diesel vehicles with a DPF and SCR, and sodium $\left(\mathrm{Na}^{+}\right)$was the most abundant species for the CNG vehicle. NOx and PM emissions were compared to, and show generally good agreement with, the latest California mobile source model (EMFAC2014).

Keywords Heavy-duty truck - Portable emission measurement system - Nitrogen oxides - Selective catalytic reduction - Diesel particulate filter - On-road testing .

Freight . Greenhouse gas

\section{Introduction}

Extensive human epidemiological and animal exposure studies have demonstrated short-term and chronic health effects from exposure to both ozone $[1,2]$ and fine particulate matter (PM) [3-6]. Emissions reductions for nitrogen oxides (NOx) and PM are needed in many areas of California and the USA, especially in regions that are in nonattainment of the National Ambient Air Quality Standards (NAAQS) for ozone and fine PM [7-9]. Onroad heavy-duty (HD) trucks are not only responsible for the largest fraction of freight emissions in California, which statewide is responsible for $50 \%$ of diesel PM, $45 \%$ of the nitrogen oxides (NOx), and $6 \%$ of the greenhouse gas (GHG) emissions [10] but also are the category of mobile sources with the greatest fuel consumption in the USA [11]. New HD on-road engines manufactured to the model year (MY) 2010 standard have $97 \%$ lower NOx and PM emissions than engines manufactured to the MY 1987 emission standard; these current limits are $0.2 \mathrm{~g} \mathrm{NOx} /$ bhp-h and $0.01 \mathrm{~g}$ PM/bhp-h when tested over the Federal Test 
Procedure (FTP) and Supplemental Emission Test (SET) cycles. However, additional stringency is needed to achieve several air quality goals in the coming decades, most notably, attainment of ambient air quality standards for ozone. Near-term strategies to reduce criteria pollutant emissions in California over the next 5 years include turning over the heavy-duty fleet through implementation of the Statewide Truck and Bus Regulation, adopting more stringent certification, in-use compliance, and warranty reporting requirements $[12,13]$. Thereafter, additional in-use regulations or incentive programs may be needed to accelerate the adoption of newer technologies and adopting more stringent certification standards [14].

In-use programs that are used to accelerate the adoption of newer technologies into the long-lived fleet are important because the median lifetime mileage accrual for a heavy-HD (HHD, > 33,000 lbs gross vehicle weight rating, GVWR) vehicle operating in the USA is nearly $800,000 \mathrm{mi}(1,290,000 \mathrm{~km})$ [12]. Accordingly, the California Air Resources Board (CARB) adopted the Truck and Bus Regulation in 2008 [15], which requires phasing-out older equipment and the adoption of MY 2010 or newer engine technology in several regions of the state by 2023 to accelerate emissions reductions for NOx and PM [9, 16]. More recently, CARB adopted an optional low-NOx standard where engine manufacturers can certify new engines to levels $50-90 \%$ below the current standard of $0.2 \mathrm{~g} \mathrm{NOx} / \mathrm{bhp}-$ $\mathrm{h}$ [17]. However, emissions of NOx or other pollutants during real-world driving activities may exceed levels measured during certification under controlled laboratory conditions using an engine dynamometer [18]. Elevated emissions could result from poor durability of emission control devices (e.g. selective catalytic reduction (SCR), or diesel particulate filter (DPF) systems) [16], the generation of off-cycle NOx emissions when SCR temperatures are below catalyst light-off temperatures $[19,20]$, or emissions generated during infrequent events such as DPF regeneration that are quantified during certification but may exhibit different emissions trends during real-world operation [21, 22]. Improved control of actual in-use emissions, which include these known types of off-cycle events, begins with identifying the periods of inefficient emission control during real-world driving, especially during the introduction of new engine and aftertreatment technologies to achieve stringent emission standards.

To better understand emissions trends, HD on-road vehicles can be tested in the laboratory on a chassis dynamometer, or over the road using modern portable emissions measurement systems (PEMS), which can also be used to enforce notto-exceed (NTE) emission limits [23, 24]. An alternative approach to using PEMS is to use a full-scale mobile laboratory compliant to Code of Federal Regulations (CFR) Part 1065 for emissions measurement, which is housed in a tractor trailer for operation on the roadway $[25,26]$. A recent study using the full-scale mobile laboratory approach [27] found that brakespecific NOx emissions were below $0.2 \mathrm{~g} / \mathrm{bhp}-\mathrm{h}$ for a cross- continental trip across the USA consisting predominately of high-speed interstate highway driving.

This study includes additional on-road measurements from HD vehicles and expands upon the cross-continental measurements by including test routes with congested traffic conditions and other low-speed operations that have been shown to increase NOx emissions from SCR-equipped HD diesel trucks [19]. Emissions occurring under these operational conditions will likely impact the South Coast Air Basin's attainment strategy for ambient ozone goals in 2023 and 2031 [13]. For this evaluation, the following six driving routes were selected that are characteristic of conditions throughout the state: Hill Climb Highway, Interstate Highway, Regional Highway, Local Drayage, Near-Dock Drayage, and an Urban Arterial Route. Testing was repeated using six diesel vehicles (all six equipped with a DPF, four with SCR), and one stoichiometric compressed natural gas $(\mathrm{CNG})$ vehicle. Brake-specific and per-mile emissions are reported for carbon monoxide (CO), total hydrocarbons (THC), NOx, and PM. Selected filtercollected PM samples underwent ion chromatography (IC) to characterize the ion speciation of PM.

\section{Methods}

\subsection{Test Vehicles}

Table 1 lists the vehicles, engines, and other information for each of the seven vehicles in the study. All engines were either medium- or heavy-HD, all vehicles were classified as class 8 vehicles with a GVWR above $33,000 \mathrm{lbs}$, and test vehicle weight was approximately $68,000 \pm 1000 \mathrm{lbs}$ for the combined tractor and trailer. Vehicles were selected to represent four emission technology groups prevalent in California today, including (1) one MY 2007 diesel engine with no SCR and certified to a $2.3 \mathrm{~g} / \mathrm{bhp}-\mathrm{h}$ NOx family emission limit (FEL), (2) four MY 2013 or 2014 diesel engines equipped with SCR, three of which were certified to a $0.2 \mathrm{~g} / \mathrm{bhp}-\mathrm{h}$ NOx standard and one certified to a $0.31 \mathrm{~g} / \mathrm{bhp}-\mathrm{h}$ FEL, (3) one hybrid diesel vehicle with a MY 2011 engine with no SCR but certified to a $0.47 \mathrm{~g} / \mathrm{bhp}-\mathrm{h}$ NOx FEL, and (4) one MY 2013 compressed natural gas (CNG) 12-L engine with a three-way catalyst (TWC) certified to the $0.2 \mathrm{~g} /$ bhp-h NOx standard. All subsequent discussion referring to the MY pertains to the engine rather than the vehicle to align with the engine-based certification program in the USA. All seven engines utilized exhaust gas recirculation (EGR) as part of the emission control system. All seven engines were certified by the manufacturers with PM emissions at least three times below the current standard $(0.01 \mathrm{~g} / \mathrm{bhp}-\mathrm{h})$, and $\mathrm{CO}$ and nonmethane hydrocarbon (NMHC) emissions at least two times below current standards (15.5 g CO/bhp-h and $0.14 \mathrm{~g} \mathrm{NMHC/bhp-h).}$ Although no testing was conducted using compliance procedures, odometer readings indicated that all vehicles were still 
Table 1 HD test engines, emissions information, and vehicle details

\begin{tabular}{|c|c|c|c|c|c|c|c|}
\hline & Vehicle 1 & Vehicle 2 & Vehicle 3 & Vehicle 4 & Vehicle 5 & Vehicle 6 & Vehicle 7 \\
\hline Manufacturer & OEM 1 & OEM 1 & OEM 1 & OEM 2 & OEM 3 & OEM 4 & OEM 4 \\
\hline Engine MY & 2007 & 2013 & 2013 & 2014 & 2014 & 2011 & 2013 \\
\hline Model & Diesel & Diesel & $\mathrm{CNG}$ & Diesel & Diesel & Hybrid Diesel & Diesel \\
\hline $\begin{array}{l}\text { Aftertreatment } \\
\text { configuration }\end{array}$ & $\mathrm{DOC}+\mathrm{DPF}$ & $\mathrm{DOC}+\mathrm{DPF}+\mathrm{SCR}$ & TWC & $\mathrm{DOC}+\mathrm{DPF}+\mathrm{SCR}$ & $\mathrm{DOC}+\mathrm{DPF}+\mathrm{SCR}$ & $\mathrm{DOC}+\mathrm{DPF}$ & $\mathrm{DOC}+\mathrm{DPF}+\mathrm{SCR}$ \\
\hline Displacement (L) & 15.0 & 15.0 & 11.9 & 14.8 & 12.8 & 7.6 & 12.4 \\
\hline Rated power (hp) & 550 & 450 & 400 & 505 & 405 & 260 & 475 \\
\hline $\begin{array}{l}\text { Tractor GVWR } \\
\text { rating (lbs) }\end{array}$ & 80,000 & 80,000 & 80,000 & 80,000 & 80,000 & 61,000 & 80,000 \\
\hline Odometer (mi) & 393,174 & 123,471 & 11,142 & 110,680 & 40,420 & 34,260 & 186,389 \\
\hline $\begin{array}{l}\text { FTP Cert. NOx } \\
\text { (g/bhp-h) }\end{array}$ & 2.0 & 0.22 & 0.15 & 0.09 & 0.06 & 0.46 & 0.20 \\
\hline
\end{tabular}

within their useful emissions lifetime of less than $435,000 \mathrm{mi}$ for heavy-HD engines and 185,000 mi for medium-HD engines.

\subsection{Mobile Laboratory, Instrumentation, and Data Processing}

Figure 1 shows the configuration of the mobile laboratory, exhaust routing, and instrument configuration. All test vehicles pulled the mobile laboratory, which was affixed to a flatbed trailer along with an on-board power generator, and other emissions measurement equipment. The trailer was not equipped with any aerodynamic drag-reducing equipment, such as trailer skirts, but most of the tractor cabs included fairings and other aerodynamic equipment. The mobile lab was equipped with a constant volume sampler (CVS), which was set to approximately $1800 \mathrm{ft}^{3} / \mathrm{min}$ (CFM), from which both gaseous and PM measurements were conducted. For a full description of the mobile laboratory, refer to citations 26 and 27.
Raw exhaust was routed into the CVS of the mobile lab using a smooth-walled flexible and insulated 5-in manifold. Several high-speed raw exhaust flow modules (EFM) were placed between the flexible tubing and the inlet to the CVS that were utilized for the various PEMS that were included in the study but are not reported in this paper.

Modal gaseous measurements were collected from diluted exhaust in the CVS using a MEXA 7200d (Horiba Ltd., Japan) laboratory-grade bench analyzer reporting $\mathrm{CO}$ and $\mathrm{CO}_{2}$ using nondispersive infrared (NDIR), THC using a flame ionization detector (FID), and NOx using a chemiluminescence detector (CLD). Analyzer signals were post-processed according to CFR guidelines for performing drift correction (1065.672), intake-air humidity NOx correction (1065.670), performing dry-to-wet conversion of analyzers operating downstream of a chiller (1065.659), and for performing dilution air background correction (1065.667) CVS background-correction.

$\mathrm{PM}$ was measured from the CVS, after cyclonic separation and secondary dilution by approximately a factor of two, at a

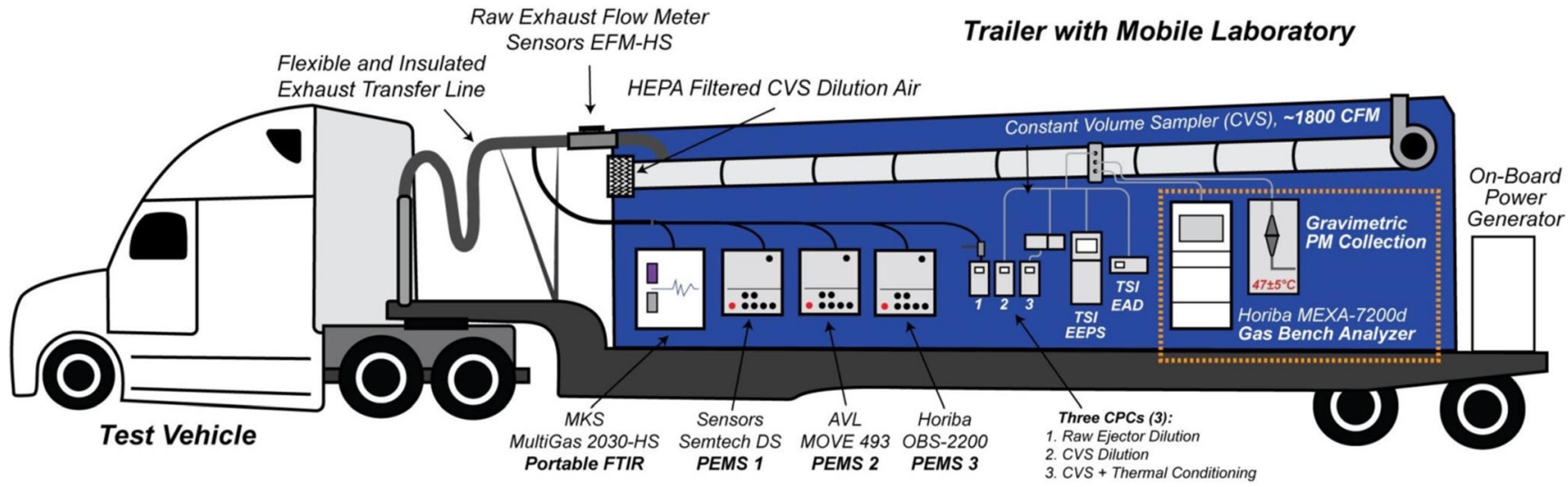

Fig. 1 Setup used for on-road testing. This study included a comprehensive suite of PEMS and real-time particulate instruments; however, this paper presents the criteria pollutants measured using the gas bench and gravimetric PM analyzers illustrated within the dotted orange box on the right-hand side of the figure. The combined weight of the tractor and trailer was approximately 68,000 lbs (color figure online) 
filter face velocity below $100 \mathrm{~cm} / \mathrm{s}$ and temperature controlled to within $47 \pm 5{ }^{\circ} \mathrm{C}$, and using polytetrafluoroethylene (PTFE)-coated quartz filter media (TX40 Emfab ${ }^{\mathrm{TM}}$, Pall Corporation, New York, NY, USA). Media were transported to a weigh-room compliant to CFR specifications at the Center for Alternative Fuels Engines and Emissions (CAFEE) in Morgantown, WV, for final gravimetric determination. Selected filter media were transported to the ARB HaagenSmit Laboratory (HSL) in El Monte, CA, for chemical characterization by ion chromatography (IC) using ARB Standard Operation Procedure (SOP) MV-AEROSOL-142 [28]. Ion concentrations were reported for sulfate $\left(\mathrm{SO}_{4}{ }^{2-}\right)$, sodium $\left(\mathrm{Na}^{+}\right)$, nitrate $\left(\mathrm{NO}_{3}{ }^{-}\right)$, calcium $\left(\mathrm{Ca}^{2+}\right)$, potassium $\left(\mathrm{K}^{+}\right)$, ammonium $\left(\mathrm{NH}_{4}{ }^{+}\right)$, magnesium $\left(\mathrm{Mg}^{2+}\right)$, and chloride $\left(\mathrm{Cl}^{-}\right)$.

Engine control unit (ECU) data were recorded using the SAE J1939 protocol over the controller area network. All vehicles broadcasted engine torques, engine speed, temperatures at various locations of the engine and aftertreatment system, and other information that allowed for quantification of brake-specific emissions during on-road operation. Some acquired data channels were not standardized and may be inconsistent among vehicles because HD on-board diagnostic (OBD) requirements were phased in between engine MY 2010 and MY 2016. For example, engine parasitic losses should be broadcast under suspect parameter number (SPN) 2978 and not included with frictional torque reported in SPN 514; however, some engines report these together, and therefore, total engine work calculated may be slightly underestimated if parasitic losses were combined with frictional losses and were both subtracted from the nominal engine torque reported in SPN 513. Other data such as aftertreatment temperatures were available from most engines but were not available for all engines. All J1939 data, emissions information, and geographical position data were logged centrally using an in-house software package.

This paper reports the emission rates and analyzes trends of $\mathrm{CO}, \mathrm{CO}_{2}, \mathrm{THC}, \mathrm{NOx}$, and PM using data reported by the laboratory-grade analyzers that sampled directly from the CVS. Several additional gaseous and particulate measurements were made, including an evaluation of commercially available PEMS systems for criteria gas measurement, the evaluation of portable Fourier-transform infrared (FTIR) spectroscopy systems for measurement of noncriteria gases such as nitrous oxide and ammonia, and measurement of several real-time suspended particulate metrics such as particle number using condensation particle counters and size distribution using electrometer-based mobility spectrometers. Only criteria pollutants are reported in this paper using the laboratory-grade analyzers to facilitate a comparison among routes, engine technologies, and engine manufacturers. The instruments used to generate data described in this paper are bounded by the orange dotted line in Fig. 1.

\subsection{Routes}

Figure 2 shows a map of the six distinct routes that were driven over at least 5 days and spanned $1500 \mathrm{mi}$ along some of the major freight corridors in California. Each day, trips were made lasting typically between 1 and $2 \mathrm{~h}$, and stops were generally made at the same locations for each truck. Thus, identical or similar trips were made across all vehicles in the study. When possible, trips over the Near-Dock Drayage, Local Drayage, Regional Highway, and Urban Arterial Routes were scheduled to occur during periods during normal business hours (09:00 to 19:00 local time) in order to capture emissions associated with commercial freight movement and capture emissions associated with any congested traffic conditions. The number of trips and mileage for each vehicle varied; some vehicles had limited range such as Vehicle 3 that operated on CNG and therefore some trips were omitted, and other trips were excluded from evaluation due to incomplete data reporting from emissions analyzers or the data acquisition system. Notwithstanding, this project stands as a comprehensive emissions measurement project for modern HD on-road engines, with capture of over $6800 \mathrm{mi}$ of second-by-second on-road emissions data from the seven vehicles.

Figure 3 illustrates the typical speed-versus-time profiles associated with each route; actual speed profiles varied for each of the trips. Annotated speeds and work per distance represent the average of all trips made over that route classification. The Hill Climb Highway Route is shown in Fig. 3a in red, which includes driving through passes on highway I-5 (i.e. the Grapevine) and highway I-15 (i.e. the Cajon Pass) to characterize emissions

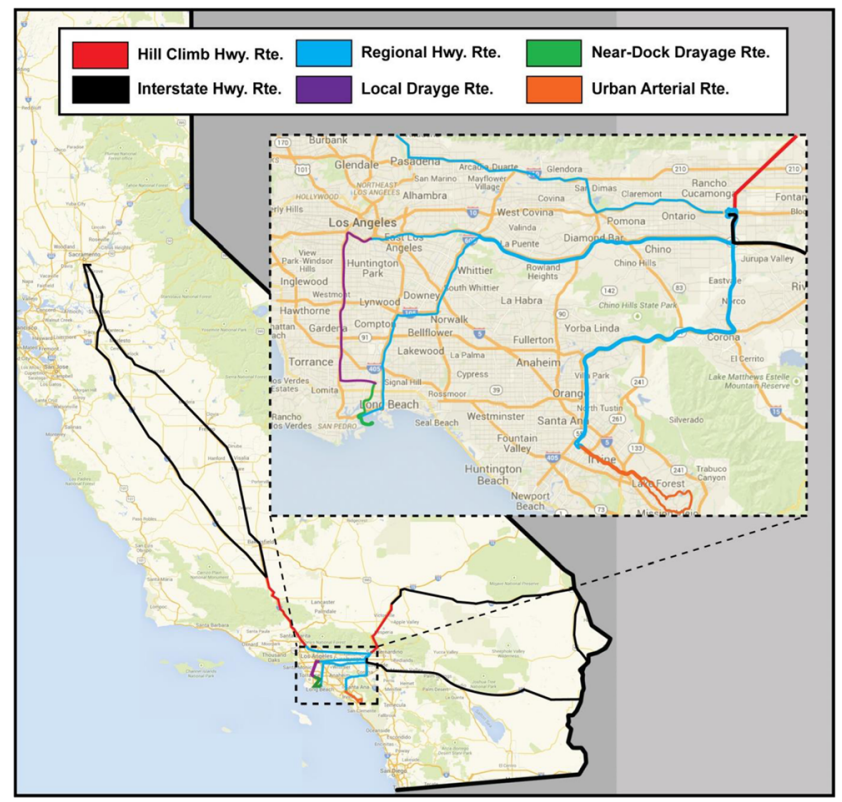

Fig. 2 Testing routes representing major freight transport corridors in California. Line color indicates the route classifications 

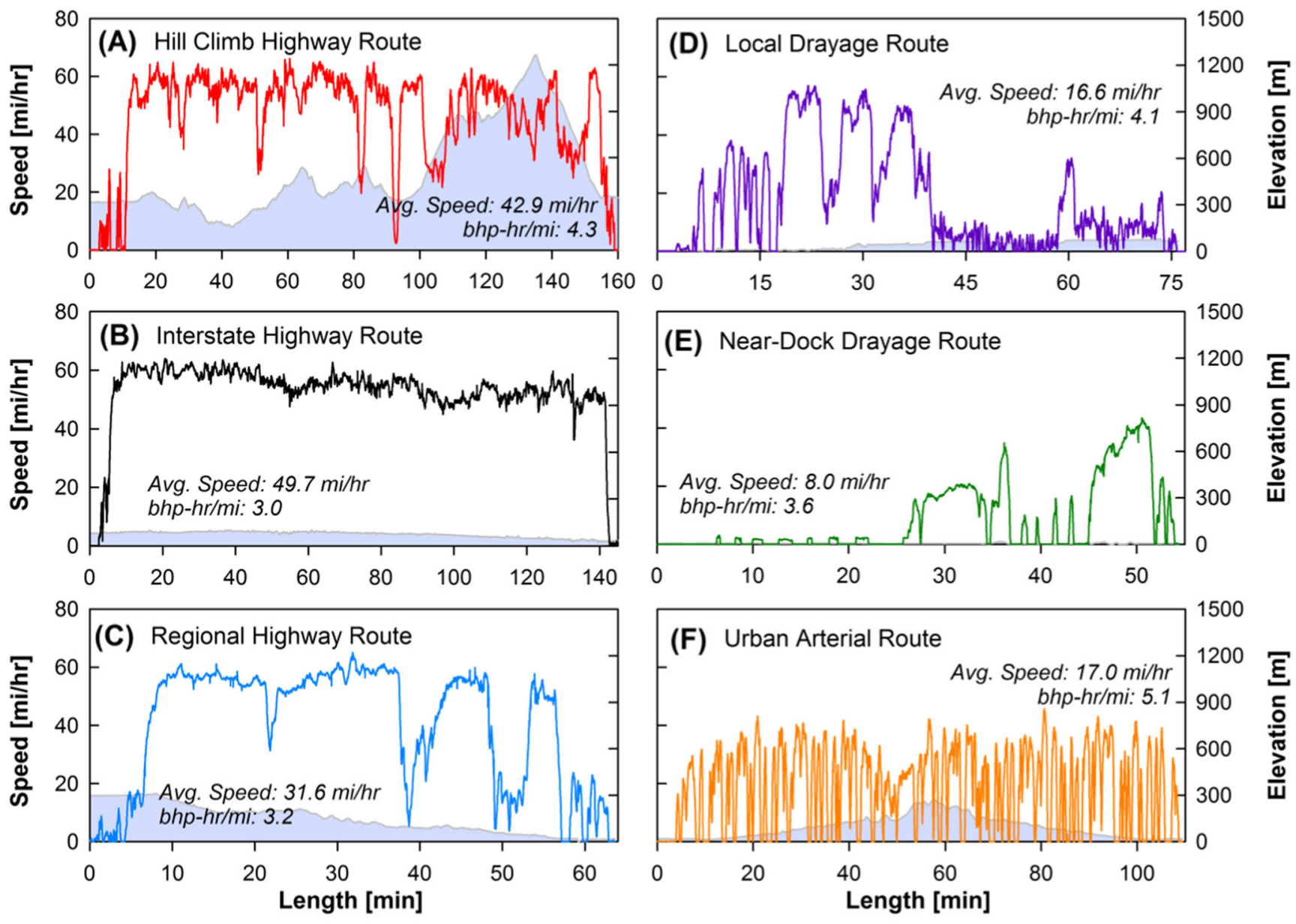

Fig. 3 Typical speed versus time for each of the six route classifications. These include the a Hill Climb Highway Route, b Interstate Highway Route, $\mathbf{c}$ Regional Highway Route, d Local Drayage Route, e Near-Dock Drayage Route, and f Urban Arterial Route

associated with freight movement in and out of the South Coast Air Basin. Figure 3b shows the Interstate Highway Route, which included driving on north-south corridors through the San Joaquin Valley on SR-99 and I-5, and on east-west corridors to the eastern California-Arizona border via SR-40 and I-10. Figure 3c shows Regional Highway Routes that included driving at speeds commonly around $55 \mathrm{mi} / \mathrm{h}$, but also frequent periods of slower congested highway driving. Drayage Routes were included to capture emissions associated with freight movement leaving the Ports of Long Beach and Los Angeles. The Near-Dock Drayage Route shown in Fig. 3e simulated the stop-and-go operations associated with cargo loading from ocean-going vessels followed by brief higher-speed driving onto local highways, and the Local Drayage Route shown in Fig. 3d simulated transport to regional rail yards near downtown Los Angeles. The sixth route was an Urban Arterial Route as shown in Fig. 3f, which included driving stop-and-go driving frequently approaching speeds around $40 \mathrm{mi} / \mathrm{h}$, which is meant to represent "last-mile" delivery of goods from a grocery distribution center to retail locations.

\section{Results}

Table 2 tabulates the average brake-specific and distancespecific emission factors by route and technology group; the ranges of route averages are presented throughout the text. Trip-to-trip variability included both measurement as well as driving condition differences; therefore, ranges of the average emission rates by route are presented rather than ranges of repeat trips over one given route classification. The standard error of the mean (SEM) for data presented in Table 2 was commonly $40 \%$ or more because of the variable on-road driving conditions. The Urban Arterial Route results are not presented for Vehicles 1 and 3 because no valid emissions measurement tests were available for these trips. Table 3 presents the average emissions by weighting each route equally by one fifth or one sixth (depending upon the vehicle) to calculate an average or overall emission rate for each vehicle. These values can be used to compare the relative performance of the vehicles on this route but do not necessarily imply an activity-weighting average for vehicles frequently using these freight transport corridors. 
Table 2 Average speed, total distance, work-to-distance ratios, and criteria pollutant emissions by engine technology group and route

\begin{tabular}{|c|c|c|c|c|c|c|c|c|c|c|c|c|c|}
\hline & \multirow{2}{*}{$\begin{array}{l}\text { Average speed } \\
(\mathrm{mph})\end{array}$} & \multirow{2}{*}{$\begin{array}{l}\text { Distance } \\
\text { (mi) }\end{array}$} & \multirow{2}{*}{$\begin{array}{l}\text { W/Dis } \\
\text { (bhp-h/mi) }\end{array}$} & \multicolumn{5}{|c|}{ Emission rate (g/mi) } & \multicolumn{5}{|c|}{ Emission rate (g/bhp-h) } \\
\hline & & & & $\mathrm{CO}_{2}$ & $\mathrm{CO}$ & $\mathrm{NO}_{\mathrm{X}}$ & THC & PM & $\mathrm{CO}_{2}$ & $\mathrm{CO}$ & $\mathrm{NO}_{\mathrm{X}}$ & THC & PM \\
\hline \multicolumn{14}{|c|}{ MY 2007 Diesel (DOC + DPF)—No SCR - Vehicle 1} \\
\hline Hill Climb & 53.2 & 74.1 & 4.3 & 2445 & 0.26 & 14.2 & 0.02 & 0.014 & 572 & 0.06 & 3.33 & 0.00 & 0.003 \\
\hline Interstate & 51.7 & 765 & 2.1 & 1484 & 0.24 & 9.16 & 0.05 & 0.008 & 694 & 0.11 & 4.29 & 0.02 & 0.001 \\
\hline Regional & 33.0 & 329 & 2.8 & 1862 & 0.31 & 11.3 & 0.11 & 0.005 & 662 & 0.11 & 4.02 & 0.04 & 0.001 \\
\hline Local Drayage & 19.6 & 22.0 & 3.7 & 2457 & 0.49 & 14.7 & 0.23 & N/A & 666 & 0.13 & 3.99 & 0.06 & N/A \\
\hline Near-Dock & 7.8 & 7.3 & 3.1 & 3015 & 1.24 & 18.3 & 0.45 & N/A & 984 & 0.40 & 5.96 & 0.15 & N/A \\
\hline \multicolumn{14}{|c|}{ MY 2013 \& 2014 SCR Diesel (DOC + DPF + SCR)-Vehicles 2, 4, 5, and 7} \\
\hline Hill Climb & 44.6 & 426 & 4.3 & 1936 & 0.45 & 0.73 & 0.04 & 0.012 & 451 & 0.11 & 0.17 & 0.01 & 0.003 \\
\hline Interstate & 50.3 & 2178 & 3.3 & 1469 & 0.30 & 0.58 & 0.02 & 0.004 & 450 & 0.09 & 0.18 & 0.01 & 0.001 \\
\hline Regional & 30.6 & 904 & 3.4 & 1680 & 0.50 & 0.79 & 0.05 & 0.005 & 499 & 0.15 & 0.24 & 0.02 & 0.002 \\
\hline Local & 16.8 & 78.0 & 4.5 & 2473 & 0.63 & 1.72 & 0.02 & 0.006 & 551 & 0.14 & 0.38 & 0.00 & 0.001 \\
\hline Near-Dock & 9.2 & 46.2 & 4.2 & 2702 & 0.67 & 3.99 & 0.15 & 0.009 & 651 & 0.16 & 0.96 & 0.04 & 0.002 \\
\hline Urban & 17.3 & 106 & 5.4 & 2701 & 0.94 & 0.88 & 0.06 & 0.009 & 497 & 0.17 & 0.16 & 0.01 & 0.002 \\
\hline \multicolumn{14}{|c|}{ MY 2013 CNG (TWC)_Vehicle 3} \\
\hline Hill Climb & 44.6 & 95.1 & 4.6 & 2108 & 9.02 & 0.42 & 3.70 & 0.002 & 461 & 1.97 & 0.09 & 0.81 & 0.000 \\
\hline Interstate & 43.8 & 260 & 2.9 & 1379 & 7.58 & 0.16 & 1.93 & 0.003 & 480 & 2.64 & 0.06 & 0.67 & 0.001 \\
\hline Regional & 33.8 & 235 & 3.1 & 1495 & 8.83 & 0.23 & 1.67 & 0.004 & 487 & 2.87 & 0.08 & 0.54 & 0.001 \\
\hline Local & 15.6 & 21.9 & 3.5 & 2214 & 14.36 & 0.46 & 1.37 & 0.008 & 628 & 4.07 & 0.13 & 0.39 & 0.002 \\
\hline Near-Dock & 9.2 & 7.4 & 3.2 & 2369 & 9.06 & 0.38 & 5.03 & 0.012 & 732 & 2.80 & 0.12 & 1.56 & 0.004 \\
\hline \multicolumn{14}{|c|}{ MY 2011 Hybrid Diesel (DOC+DPF) - No SCR_Vehicle 6} \\
\hline Hill Climb & 32.2 & 57.1 & 3.8 & 2468 & 0.63 & 3.92 & 0.13 & N/A & 654 & 0.17 & 1.04 & 0.03 & N/A \\
\hline Interstate & 36.2 & 59.4 & 2.9 & 1891 & 0.43 & 2.32 & 0.02 & N/A & 651 & 0.15 & 0.80 & 0.01 & N/A \\
\hline Regional & 31.9 & 147 & 2.8 & 1807 & 0.42 & 2.40 & 0.03 & 0.013 & 648 & 0.15 & 0.86 & 0.01 & 0.005 \\
\hline Local & 14.3 & 21.9 & 3.7 & 2475 & 1.57 & 5.03 & 0.07 & N/A & 670 & 0.42 & 1.36 & 0.02 & N/A \\
\hline Near-Dock & 6.6 & 7.4 & 3.2 & 2377 & 3.35 & 2.96 & 0.17 & 0.009 & 750 & 1.06 & 0.93 & 0.05 & 0.003 \\
\hline Urban & 15.9 & 33.7 & 4.0 & 2567 & 0.73 & 5.78 & 0.04 & N/A & 644 & 0.18 & 1.45 & 0.01 & N/A \\
\hline
\end{tabular}

Note that trips with active DPF regeneration events were excluded from PM emissions reported in this table to compare differences among routes in the absence of an infrequent event

Emissions results are reported primarily on a brake-specific basis using the broadcast engine torque and speed parameters using the J1939 protocol. Using net engine work produced, comparisons are made for each pollutant relative to engine dynamometer test data and certification limits. On-road inuse emissions measured in this study are not representative of engine dynamometer cycles such as the FTP or SET, and when emissions exceed engine dynamometer certification limits, they still may be compliant with all relevant certification and in-use standards. Still, engine emissions measured during on-road chassis-based operation are presented alongside engine certification standards to assess the relative levels of control achieved during on-road operation. Generally, onroad testing is critical to identify periods of inefficiency of emission control systems, as well as to better understand how chassis dynamometer testing can be improved to better represent on-road driving behavior.

\subsection{CO Emissions}

Figure 4a presents $\mathrm{CO}$ emissions on a brake-specific and permile basis for each route and vehicle group. For dieselpowered vehicles, emissions of $\mathrm{CO}$ were near or below $1 \mathrm{~g} /$ bhp-h, which is more than $90 \%$ below the engine dynamometer certification standard of $15.5 \mathrm{~g} / \mathrm{bhp}-\mathrm{h}$. Such low CO concentrations are achieved by using the DOC, which has become an integral and vital component of HD diesel emission control systems. For example, the DOC reduces hydrocarbons while oxidizing $\mathrm{NO}$ into $\mathrm{NO}_{2}$, which promotes passive oxidation of soot collected by the DPF. However, CO emissions could potentially increase on engines using higher EGR rates to control NOx emissions. Average $\mathrm{CO}$ emissions during realworld operation (0.09-0.17 g/bhp-h depending on route) were slightly elevated compared to engine dynamometer testing of three MY 2010-compliant engines during the Advanced 
Table 3 Average speed, total distance, and criteria pollutant emissions by vehicle and technology group

\begin{tabular}{|c|c|c|c|c|c|c|c|c|c|c|c|c|c|}
\hline & \multirow{2}{*}{$\begin{array}{l}\text { Average } \\
\text { (mph) }\end{array}$} & \multirow{2}{*}{$\begin{array}{l}\text { Distance } \\
\text { (mi) }\end{array}$} & \multicolumn{5}{|c|}{ Emission rate $(\mathrm{g} / \mathrm{mi})$} & \multicolumn{5}{|c|}{ Emission rate (g/bhp-h) } & \multirow{2}{*}{$\begin{array}{l}\text { Ratio } \\
\mathrm{NO} / \mathrm{NO}_{\mathrm{X}}\end{array}$} \\
\hline & & & $\mathrm{CO}_{2}$ & $\mathrm{CO}$ & $\mathrm{NO}_{\mathrm{X}}$ & THC & PM & $\mathrm{CO}_{2}$ & $\mathrm{CO}$ & $\mathrm{NO}_{\mathrm{X}}$ & THC & PM & \\
\hline \multicolumn{14}{|c|}{ MY 2007 Std. Diesel (DOC+ DPF) } \\
\hline Vehicle $1^{\mathrm{a}}$ & 3 & 1197 & 2253 & 0.51 & 13.54 & 0.17 & 0.008 & 716 & 0.16 & 4.32 & 0.06 & 0.003 & 0.70 \\
\hline \multicolumn{14}{|c|}{ MY 2010 Std. Diesel (DOC+DPF+ SCR)-MY 2013 and MY 2014 engines } \\
\hline Vehicle $2^{\mathrm{a}}$ & 30.9 & 1580 & 2015 & 0.26 & 2.20 & 0.05 & 0.005 & 541 & 0.07 & 0.57 & 0.01 & 0.002 & 0.88 \\
\hline Vehicle 4 & 27.7 & 872 & 2048 & 0.45 & 1.05 & 0.02 & 0.007 & 533 & 0.12 & 0.29 & 0.01 & 0.002 & 0.88 \\
\hline Vehicle 5 & 28.9 & 672 & 2116 & 1.50 & 1.37 & 0.03 & 0.006 & 486 & 0.34 & 0.32 & 0.01 & 0.002 & 0.65 \\
\hline Vehicle $7^{\mathrm{b}}$ & 24.5 & 614 & 2390 & 0.32 & 1.03 & 0.14 & 0.018 & 507 & 0.07 & 0.21 & 0.03 & 0.004 & 0.83 \\
\hline \multicolumn{14}{|c|}{ MY 2010 Std. CNG (TWC)-MY 2013 engine } \\
\hline Vehicle $3^{\mathrm{a}}$ & 28.1 & 620 & 1913 & 9.77 & 0.33 & 2.74 & 0.004 & 558 & 2.87 & 0.09 & 0.79 & 0.001 & 0.96 \\
\hline \multicolumn{14}{|c|}{ Hybrid Diesel (DOC+DPF) - No SCR - MY 2011 engine } \\
\hline Vehicle 6 & 22.9 & 327 & 2264 & 1.19 & 3.74 & 0.07 & 0.016 & 670 & 0.36 & 1.07 & 0.02 & 0.005 & 0.67 \\
\hline
\end{tabular}

Emissions assessed over each route are equally averaged into the figures below regardless of driving distance, engine work, or number of trips made for each route. Note that trips with active DPF regeneration events were not excluded from PM emissions reported in this table to compare the overall PM emissions measured from each vehicle technology

${ }^{a}$ Average does not include Urban Arterial Route.

${ }^{\mathrm{b}}$ Average does not include Hill Climb Highway Route

Collaborative Emissions Study (ACES) Phase II (0.02-0.1 g/ still substantially lower than the relevant engine dynamometer bhp-h) evaluated over the FTP and 16-h cycles [29] but were certification limit.

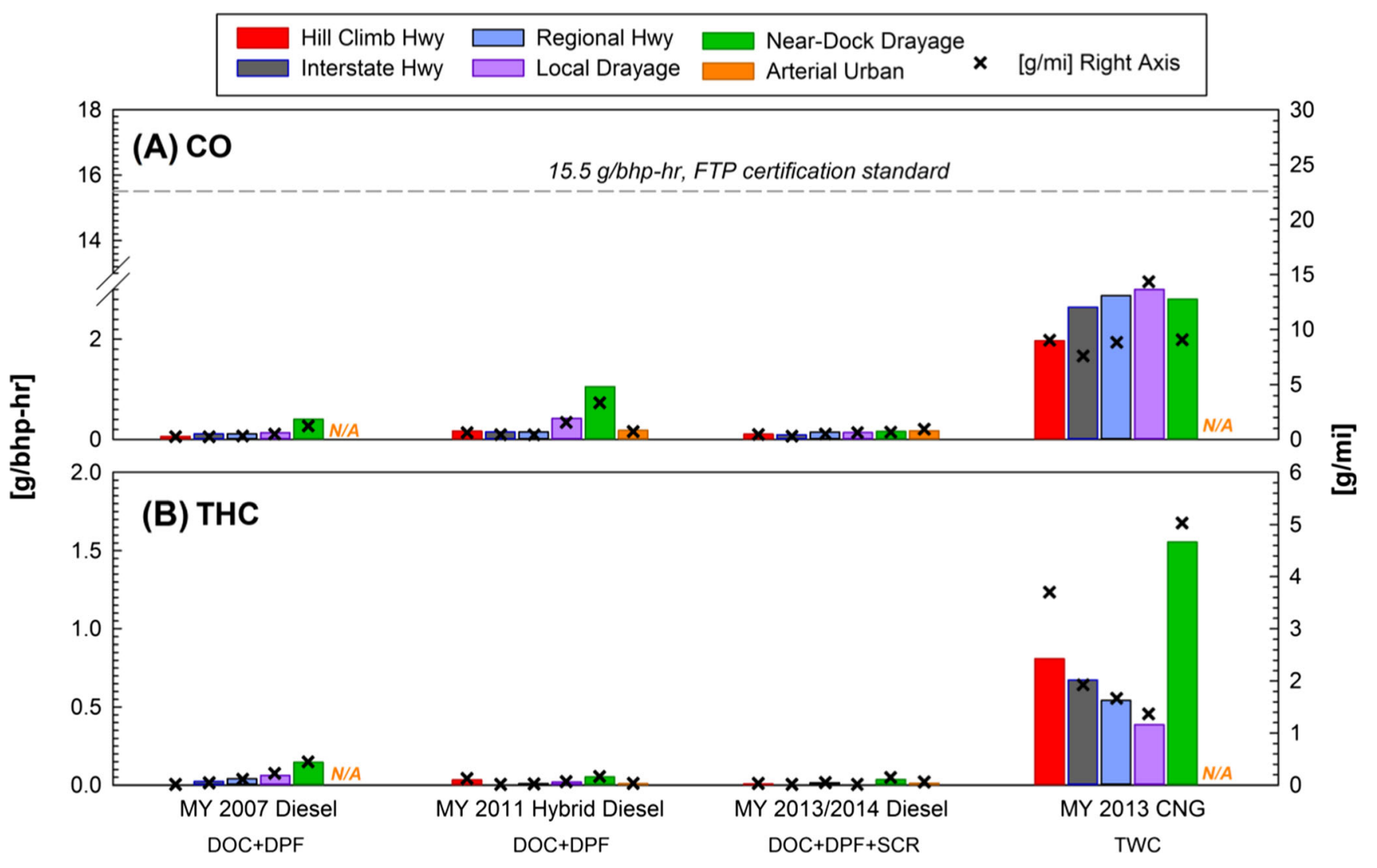

Fig. 4 Average a CO and b THC emissions grouped by engine technology and route type 
The CNG vehicle had route average emissions ranging from 1.97 to $4.07 \mathrm{~g} \mathrm{CO} / \mathrm{bhp}-\mathrm{h}$. Despite higher CO emissions from the CNG compared to diesel vehicles, brake-specific emissions were at least three times below the engine dynamometer certification standards. Earlier chassis dynamometer testing of TWCequipped CNG buses with MY 2007-2011 Cummins 8.9-L engines reported $\mathrm{CO}$ emissions between 6 and $27 \mathrm{~g} / \mathrm{mi}$ over various vocational and standard chassis dynamometer driving cycles [30, 31]; per-mile emissions reported from the $12-\mathrm{L} \mathrm{CNG}$ engine in this study was 7.6-14.4 $\mathrm{g} / \mathrm{mi}$ indicating comparable levels of control by stoichiometric combustion and TWC aftertreatment. Generally for both $\mathrm{CNG}$ and diesel-powered vehicles in this study, CO emissions were lower for routes with higher vehicle load and speeds, and emissions were slightly higher for lowerspeed driving in Near-Dock and Local Drayage Routes.

\subsection{THC Emissions}

Figure $4 \mathrm{~b}$ presents THC emissions on a brake-specific and permile basis for each route and vehicle group. The relevant emission certification standard for MY 2007 and newer engines is $0.14 \mathrm{~g}$ nonmethane hydrocarbons (NMHC)/bhp-h, which does not consider emissions of methane that is also detected by the MEXA 7200d flame-ionization detector (FID) used to report $\mathrm{THC}$ in this study.

Route average THC emissions ranged from 0.00 to 0.15 , from 0.00 to 0.04 , and from 0.01 to $0.05 \mathrm{~g} / \mathrm{bhp}-\mathrm{h}$ for the MY 2007 diesel, MY 2013 and MY 2014 SCR diesel, and MY 2011 hybrid diesel engine groups, respectively. Similar to the level of control for $\mathrm{CO}$, lean combustion with DOC aftertreatment achieved emissions of about three times or more below the relevant engine dynamometer certification standard during on-road operation, and higher than the emission factors reported during the ACES II study ( $0.001 \mathrm{~g} / \mathrm{bhp}-\mathrm{h})$ [29]. The procedure used in the ACES cycle favored very low THC concentrations because it reflects the average of repetitive hot starts over several hours and also does not consider on-road conditions that are important for inventory development.

For diesel vehicles, where low THC concentrations are typically observed (raw exhaust THC concentrations typically 12 ppm), measurement accuracy may be affected by background concentrations in the dilution air. Particulate but no gaseous removal is achieved by the filtration of CVS dilution air, and analyzer drift corrections do not consider fluctuations in on-road background concentrations of the dilution air used for emissions measurement. If raw exhaust concentrations approach the onroad background concentrations used in dilution air, more accurate THC measurement may be achieved using a raw exhaust analyzer (the principle used by PEMS) rather than analyzing dilute emissions from the CVS.

The CNG engine emitted between 0.39 and $1.56 \mathrm{~g}$ THC/bhp$\mathrm{h}$ when averaged for each route. While these THC results are an order of magnitude higher than the NMHC certification standard, they are unlikely to indicate an exceedance of the NMHC standard due to cross sensitivity of the THC detector to methane, which has been shown in previous studies to account for $\sim 95 \%$ of the THC signal for stoichiometric CNG engines equipped with TWC [30].

\subsection{NOx Emissions}

\subsubsection{MY 2007 Diesel Vehicle (No SCR)}

Figure 5 shows $\mathrm{NO}, \mathrm{NO}_{2}$, and $\mathrm{NOx}$ emissions on a brakespecific and per-mile basis for each route and vehicle group. The MY 2007 diesel engine had the highest range

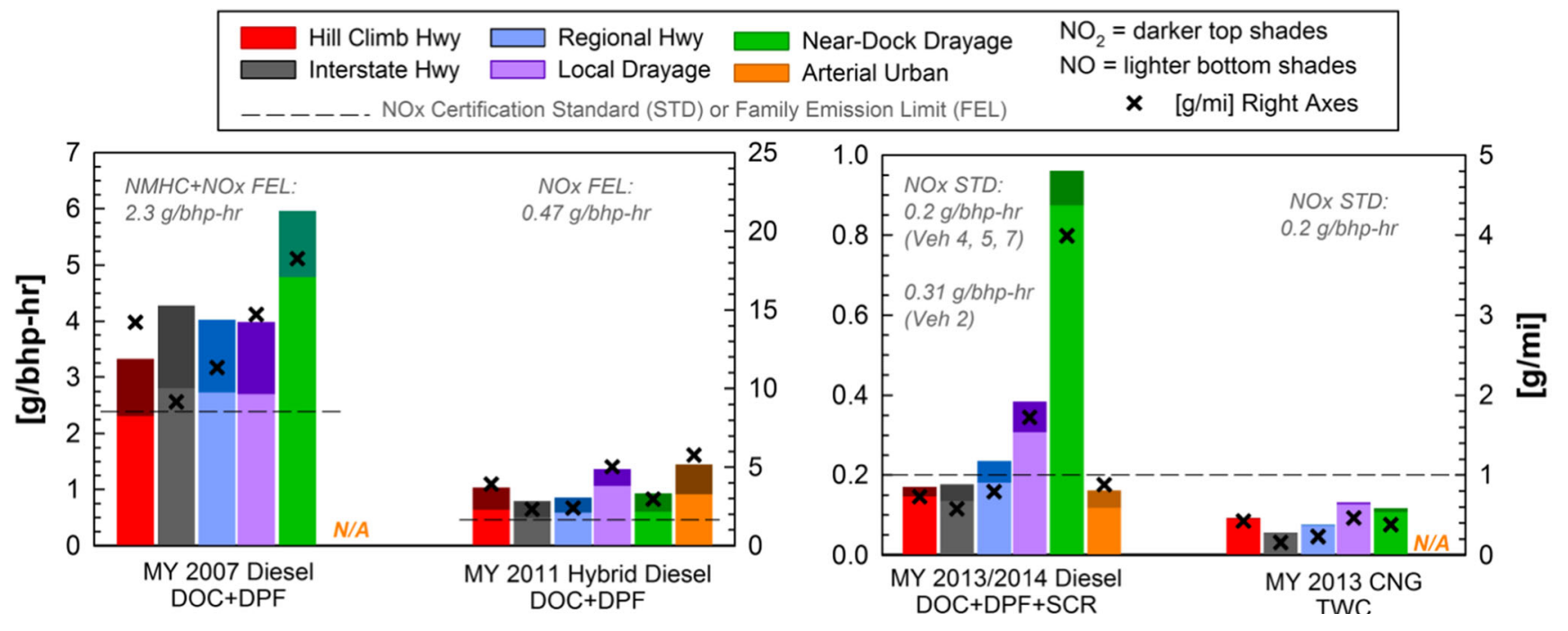

Fig. 5 Average NOx emissions grouped by engine technology and route type 
of NOx route-average emissions (3.33-5.96 g/bhp-h), which was greater than the engine dynamometer family emission limit (FEL) of $2.3 \mathrm{~g} \mathrm{NOx}+\mathrm{NMHC} / \mathrm{bhp}-\mathrm{h}$ to which the engine was certified. Many of these routes are not within the scope of current HD regulations, especially the Near-Dock Route (average emissions of $5.96 \mathrm{~g} / \mathrm{bhp}-\mathrm{h}$ and $18.3 \mathrm{~g} / \mathrm{mi}$ ), which included lowerspeed and stop-and-go operation. For other routes such as the Hill Climb Highway (average emissions of $3.33 \mathrm{~g} /$ bhp-h and $14.2 \mathrm{~g} / \mathrm{mi}$ ), some operation likely occurred within the Not-To-Exceed (NTE) window [32] for which this engine was subject to a more lenient $2.9 \mathrm{~g} / \mathrm{bhp}-\mathrm{h}$ emission limit (NMHC + NOx); however, emissions during NTE windows are not reported or analyzed here. The average NO to NOx ratio was 0.70 for this vehicle (Table 3) and was relatively similar for all routes.

\subsubsection{Diesel Vehicles with SCR}

The two MY 2013 and two MY 2014 diesel vehicles with SCR had route average NOx emissions below the $0.2 \mathrm{~g} / \mathrm{bhp}-\mathrm{h}$ standard for Hill Climb Highway $(0.17 \mathrm{~g} /$ bhp-h), Interstate Highway (0.18 g/bhp-h), and Urban Arterial $(0.16 \mathrm{~g} / \mathrm{bhp}-\mathrm{h})$ routes, had slightly increased averages for Regional Highway and Local Drayage Routes ( 0.24 and $0.38 \mathrm{~g} / \mathrm{bhp}-\mathrm{h}$, respectively), and emitted about five times the certification standard over the Near-Dock Route $(0.96 \mathrm{~g} / \mathrm{bhp}-\mathrm{h})$. Over all routes, emissions on a per-mile basis range between 0.6 and $4.0 \mathrm{~g} / \mathrm{mi}$, which was slightly lower than the range of $2.0-8.9 \mathrm{~g} / \mathrm{mi}$ reported by Thiruvengadam et al. [31] over the chassis dynamometer UDDS cycle for MY 2010 and 2011 engines all equipped with SCR. Whereas these results indicate later
MY engines have improved NOx control, the SCR conversion efficiency decreases at a threshold temperature somewhere between 200 and $250{ }^{\circ} \mathrm{C}$ [20, 31], and elevated brake-specific and per-mile NOx emissions were still observed during low-load driving conditions.

Figure 6 presents NOx emissions separately by the four SCR diesel vehicles as route averages and where applicable standard deviations are presented. Vehicle 2 (MY 2013 15.0-L OEM 1) had the highest NOx emissions for all routes of all the SCR diesel vehicles. Its certification NOx was also the highest of the four vehicles $(0.22 \mathrm{~g} /$ bhp-h, Table 1); however, the certification value for Vehicle 7 (MY 2013, 12.4-L OEM 4) was the second highest $(0.20 \mathrm{~g} / \mathrm{bhp}-\mathrm{h})$, and this vehicle resulted in the lowest or nearly the lowest NOx emissions for any diesel vehicle over all routes. Vehicle 4 (MY 2014 15-L OEM 2) and Vehicle 5 (MY 2014 12.8-L OEM 3) were certified at 0.09 and $0.06 \mathrm{~g} / \mathrm{bhp}-\mathrm{h}$, respectively, but realworld NOx emissions were higher than Vehicle 7 which has a certification NOx level of $0.20 \mathrm{~g} / \mathrm{bhp}-\mathrm{h}$. For instance, Vehicle 7 emitted $0.04 \mathrm{~g} / \mathrm{bhp}$-h over the Interstate Highway Route which was five times lower than the certification value, whereas Vehicles 4 and 5 emitted 0.16 and $0.18 \mathrm{~g} / \mathrm{bhp}-\mathrm{h}$ over the Interstate Highway Route, which exceeded their certification values by at least $50 \%$. Thus, certification NOx emissions alone do not appear sufficient to predict the in-use NOx emissions from a particular HD diesel engine equipped with SCR.

To illustrate trends of real-world routes with high NOx emissions for all engine manufacturers, Fig. 7 presents cumulative NOx emissions from the SCR diesel vehicles for the Near-Dock Route along with a typical

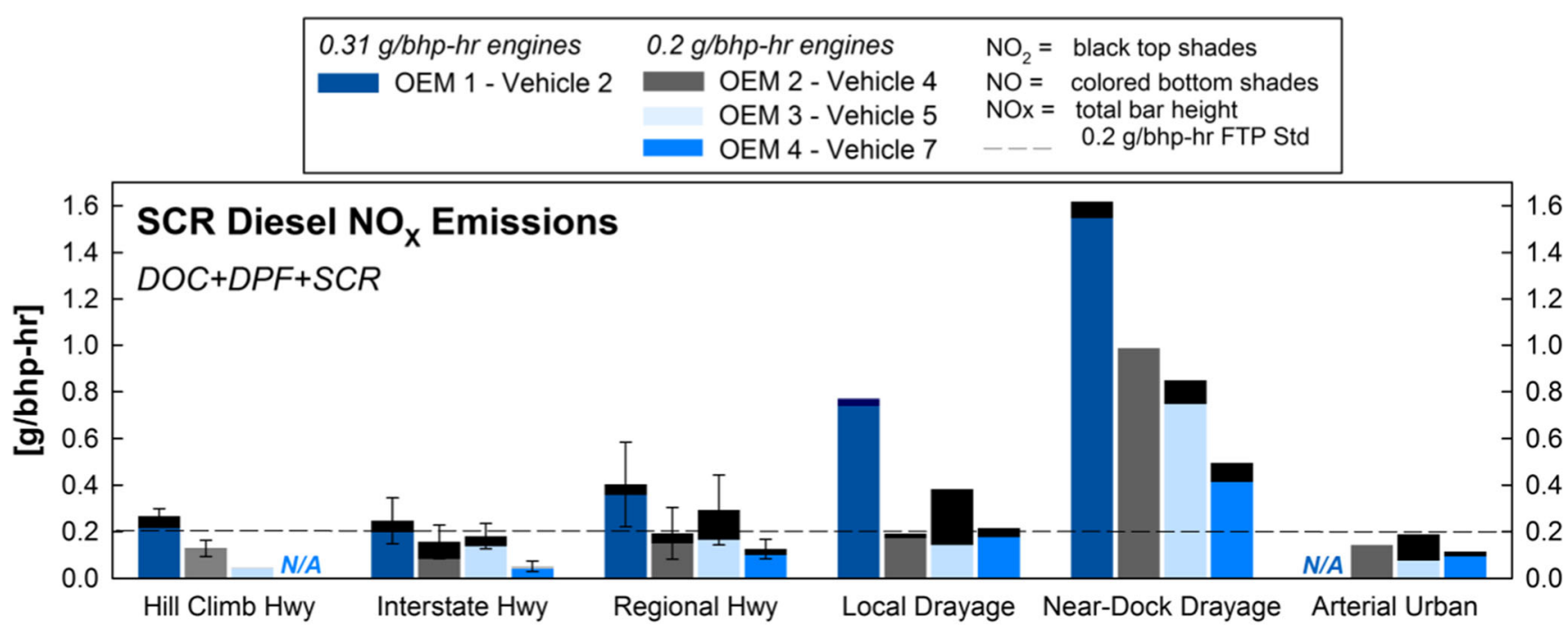

Fig. 6 Average NOx emissions for diesel engines with SCR and certified to the 0.2 or $0.31 \mathrm{~g} / \mathrm{bhp}-\mathrm{h}$ NOx emission standard. Error bars indicate plus and minus one standard deviation. Data with no error bars indicate that one trip was performed 
Fig. 7 Cumulative NOx emissions for the SCR-equipped vehicles as a function of distance over the Near-Dock Drayage Route. SCR inlet temperatures are shown for the vehicles broadcasting this parameter. The bottom pane shows the speed versus time trace, which illustrates more clearly the creeping behavior occurring during the first mile of the route

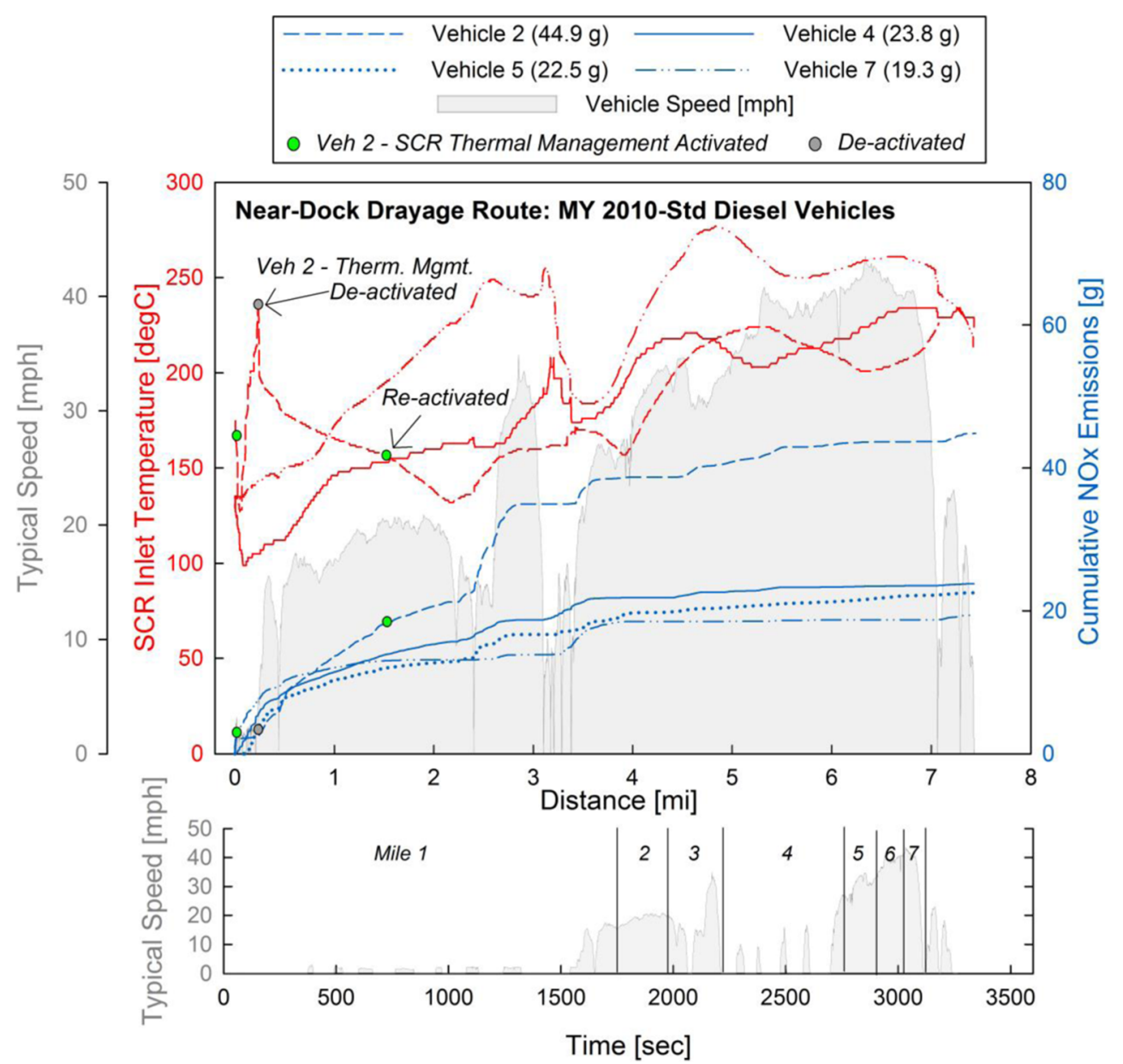

speed profile. The trends in NOx emissions versus distance over the route were similar for Vehicles 4, 5, and 7, whereas cumulative emissions were about two times higher from Vehicle 2. SCR inlet temperatures were broadcast and available for Vehicle 2 (dashed red line), Vehicle 4 (solid red line), and Vehicle 7 (dot-dashed red line). These data show that the SCR inlet temperature for Vehicle 2 increased to nearly $250{ }^{\circ} \mathrm{C}$ during the first mile of the route due to the activation of an SCR thermal management system that was indicated by a Boolean operator in the J1939 broadcast data. Following deactivation, the SCR inlet temperature decreased and NOx emissions increased and accumulated at an accelerated rate, despite reactivation of the thermal management at around $1.5 \mathrm{mi}$ into the route. Although the ECM on Vehicle 2 broadcasted information describing activity of a thermal management system, this does not indicate the absence of thermal management by the other three OEMs, and use of such a system on Vehicle 2 did not achieve better control of NOx compared to the other OEMs. Although we confirmed that the same Cummins SCR hardware was equipped on multiple trucks, the operational strategy and calibration appears to result in different thermal management strategies achieving various levels of NOx control. The NearDock Route was associated with low-speed driving conditions and operation below SCR light-off temperatures; however, the range of average NOx emission rates for any of the vehicles $(0.50-1.62 \mathrm{~g} / \mathrm{bhp}-\mathrm{h})$ was still $73-$ $92 \%$ lower than the trip-average NOx emission rate from the MY 2007 diesel engine with no SCR (5.96 g/bhp-h). This suggests that engine-out NOx from the MY 2013 and 2014 diesel engines may be lower than engine-out emissions from the MY 2007 diesel engine through optimization of EGR, fuel injection, or other parameters to help reduce peak combustion temperature.

The NO to NOx ratio was 0.82 for the SCR diesel vehicles, which was slightly greater than the ratio from MY 2007 diesel engine (0.70). Similarly, the ratio did not show strong route dependency, although Vehicle 5 (MY 2014 12.8-L, OEM 3) had the lowest ratio (0.65) compared to the other three SCR diesel engines (0.83$0.88)$. 


\subsubsection{MY 2013 CNG Vehicle (TWC)}

Figure 5 shows that the $\mathrm{CNG}$ vehicle maintained average NOx emissions below the $0.2 \mathrm{~g} / \mathrm{bhp}$-h standard for all routes in the program. Near-Dock Drayage Route NOx emissions $(0.13 \mathrm{~g} /$ bhp-h) were $85 \%$ lower than the lowest-emitting SCR diesel vehicle, and $97 \%$ lower than the MY 2007 diesel vehicle using EGR alone without SCR. On Interstate Highway Routes, brakespecific NOx emissions $(0.06 \mathrm{~g} / \mathrm{bhp}$-h) were three times lower the average of the four SCR diesel engines $(0.18 \mathrm{~g} / \mathrm{bhp}-\mathrm{h}$, Table 2). The NO to NOx ratio was the highest for all engine technologies evaluated from the $\mathrm{CNG}$ engine (0.96) indicating the lowest degree of oxidation of $\mathrm{NO}$ when exiting the tailpipe.

Further improvements are anticipated in NOx control of HD CNG or diesel engines certified to the ARB Optional Low NOx standards of 0.10, 0.05, and $0.02 \mathrm{~g}$ NOx/bhp-h using new control strategies that could achieve additional certification and real-world NOx reductions. The first such CNG engine was certified to the $0.02 \mathrm{~g} / \mathrm{bhp}-\mathrm{h}$ Optional Low NOx Standard in late 2015 and is expected to enter the market in 2016 [33].

\subsubsection{MY 2011 Hybrid Diesel Vehicle (No SCR)}

The engine used as part of the hybrid-electric tractor was certified to $0.46 \mathrm{~g} \mathrm{NOx} / \mathrm{bhp}$-h over the FTP and was not equipped with SCR for NOx control. NOx emissions were the lowest over Interstate Highway Routes ( $0.80 \mathrm{~g} / \mathrm{bhp}-\mathrm{h}$ and $2.32 \mathrm{~g} / \mathrm{mi})$ and were the highest over the Urban Arterial Route (1.45 g/ bhp-h and $5.78 \mathrm{~g} / \mathrm{mi}$ ) as shown in Fig. 5. This engine employed strategies to achieve an intermediate NOx value less stringent than the $0.2 \mathrm{~g} / \mathrm{bhp}-\mathrm{h}$ standard, but more stringent than the $2.3 \mathrm{~g} / \mathrm{bhp}-\mathrm{h}$ emission standard the MY 2007 engine. Therefore, a comparison of the hybridized drivetrain on NOx emissions compared to conventional technologies for an engine with this NOx certification limit cannot be made using this dataset. The brake-specific work broadcast by the ECU only reflects engine work; any stored electric energy that was recovered during regenerative braking was not considered in total engine work or brake-specific emission factors. The NO to NOx ratio from the diesel hybrid engine was 0.67 when weighting equally all routes, indicating a greater degree of oxidation when leaving the tailpipe compared to other vehicles tested. Innovative technologies such as these hybridelectric drivetrains are still under development and are potential pathways for achieving both lower GHG and criteria pollutant (i.e. NOx) emissions. This is especially the case for sectors with short-haul operations, as discussed in the ARB Mobile Source Strategy document [13], which outlines several pathways toward achieving and implementing advanced and innovative HD on-road technologies to achieve air quality targets in the coming decades.

\subsubsection{Trip-Average NOx Emissions and EMFAC2014 Predictions}

Figure 8 shows average NOx emissions versus speed along with the modeled emission rate from the most applicable category that includes the test vehicle(s) from the California mobile source emissions inventory (EMFAC2014, dashed gray line). EMFAC emission rates were obtained from the Technical Documentation Handbook [34], which defines the zero mile rates (ZMR) and speed correction factors (SCF) for many truck categories. The ZMR is defined in EMFAC as the

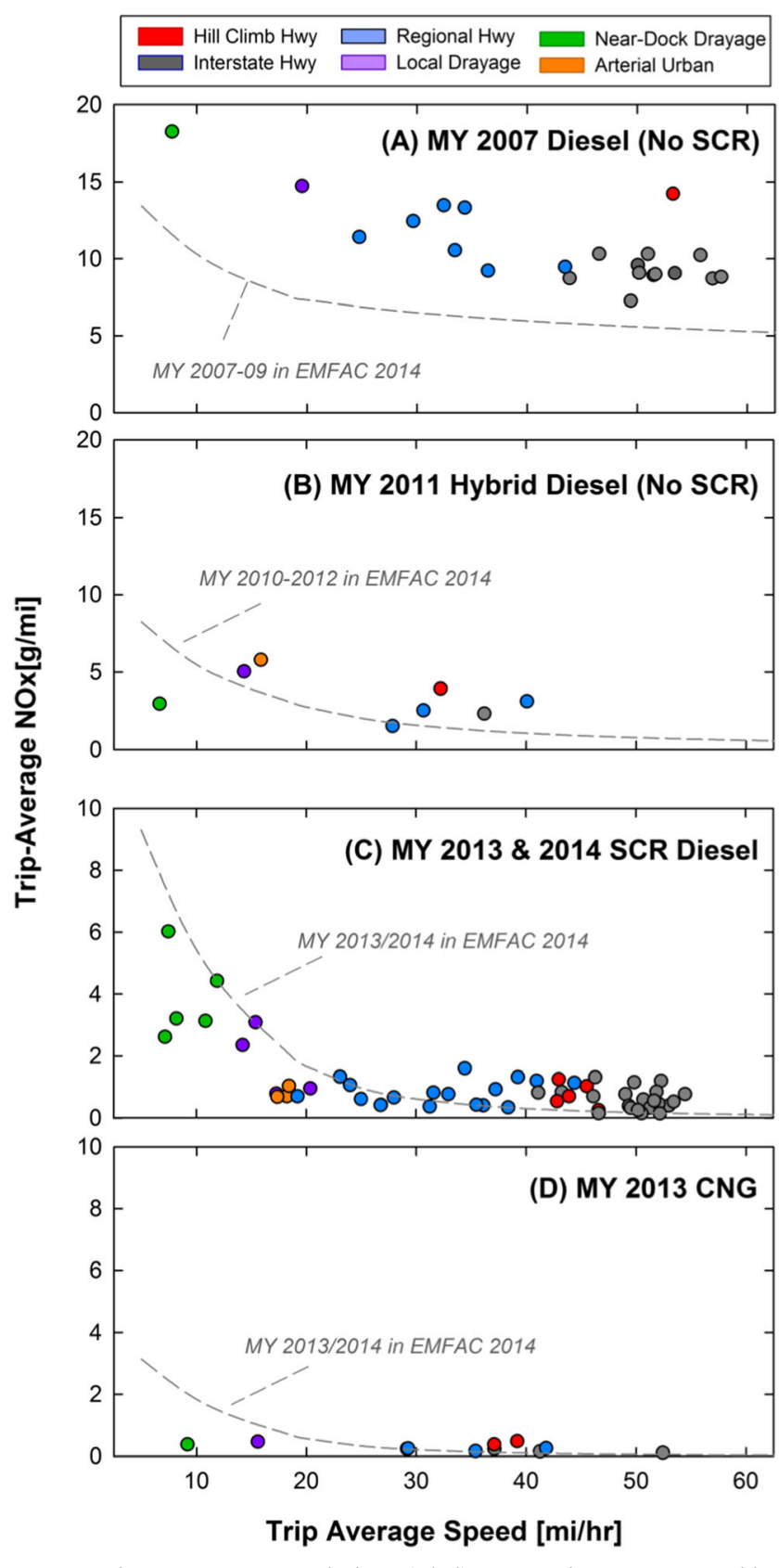

Fig. 8 Trip-average NOx emissions (g/mi) versus trip-average speed by engine technology group. Each data point represents one unique vehicletrip typically lasting between 1 and $2 \mathrm{~h}$ 
emission rate over the UDDS chassis dynamometer cycle (average speed $18.86 \mathrm{mi} / \mathrm{h}$ ) when the emission control system has not undergone any deterioration. The SCF defines how emissions changes as a function of speed, which is defined by one or more empirical constants derived from experimental data used to develop the model. In the actual model, EMFAC includes the emission control system deterioration rate (DR) based on engine MY and mileage, but DRs were not used to calculate rates used for comparison.

Figure 8a shows change of emission rates versus average trip speed from the MY 2007 diesel vehicle track well with the EMFAC projection but was overall slightly higher than the average emission rates defined by the ZMR used for MY 2007-2009 engines in the model. This is likely because the engine in this study was certified to a $2.3 \mathrm{~g} / \mathrm{bhp}-\mathrm{h}$ NOx standard, whereas the majority of engines in this subgroup were certified to a $1.2 \mathrm{~g} / \mathrm{bhp}-\mathrm{h}$ standard.

The MY 2011 hybrid diesel engine shown in Fig. 8b was also not equipped with SCR but was certified to a lower NOx standard $(0.47 \mathrm{~g} / \mathrm{bhp}-\mathrm{h})$ than the MY 2007 diesel engine. EMFAC2014 does not model emission rates for hybrid vehicles; using certification NOx values, we assumed that this vehicle had a ZMR of 3.5 g NOx/mi and applied the MY 2010-2012 diesel engine SCF, which is defined in Sect. 3.2.3.4 of the Technical Documentation Handbook. Measured data are scattered about the modeled prediction, showing generally good estimation of emissions across a range of speeds. As hybridized and other advanced drivetrains penetrate the on-road fleet, additional testing would be necessary to better model NOx emissions as a function of speed, especially including engines representative of the fleet technology moving forward, i.e. that are certified to at least the $0.2 \mathrm{~g} / \mathrm{bhp}-\mathrm{h}$ NOx standard.

In Fig. 8c, we show that emissions from the MY 2013 and 2014 SCR diesel vehicles are slightly lower than predicted by EMFAC for speeds below $20 \mathrm{mi} / \mathrm{h}$ and are slightly higher than predicted by EMFAC at speeds above $40 \mathrm{mi} / \mathrm{h}$. Note the adjusted $y$-axis scale for panels (c) and (d) to better depict the data within its range. Because two MY 2013 and two MY 2014 engines were included in this group, the arithmetic mean of the ZMR for the two model years was used to derive the ZMR ( $2.1 \mathrm{~g} \mathrm{NOx} /$ mi). Because EMFAC2014 was developed based on testing of MY 2010 and 2011 engines, these data may indicate that thermal management strategies at lower speeds have somewhat improved with subsequent engine MYs. However, high off-cycle NOx emissions are still observed at lower speeds (Figs. 5, 6, and 7), and planned regulatory measures in California will be incorporating the lower-load driving conditions that are currently beyond the scope of any HD on-road vehicle certification procedures [13]. Furthermore, measured trip-average data do not suggest that distance-based emission rates continue to decrease with speed beyond $20 \mathrm{mi} / \mathrm{h}$ as predicted by the model.

Figure 8d shows emissions from trips made by the MY 2013 CNG vehicle and the EMFAC prediction based on the parameters defined for $\mathrm{CNG}$ urban buses in the model. Even for trips with low average speeds, the CNG vehicle exhibited strong control of NOx emissions, where emission rates for all trips were below $0.5 \mathrm{~g} / \mathrm{mi}$. The EMFAC prediction is slightly under measured data at higher speeds, suggesting that like diesel vehicles, there may be a need to better quantify the emissions of trips with higher average speeds to further improve current emission inventories. Although at the current time natural gas vehicles represent only about $5 \%$ of the HD vehicle market [12], improved modeling of these vehicles will be needed to assess the implications of wider spread fleet penetration.

\subsection{PM Emissions}

\subsubsection{Emission Rates by Route and Vehicle Technology Group}

Figure 9 and Table 2 present the PM emissions on a brakespecific and per-mile basis for the vehicle and route classifications in the study. All engines were certified to levels at least three

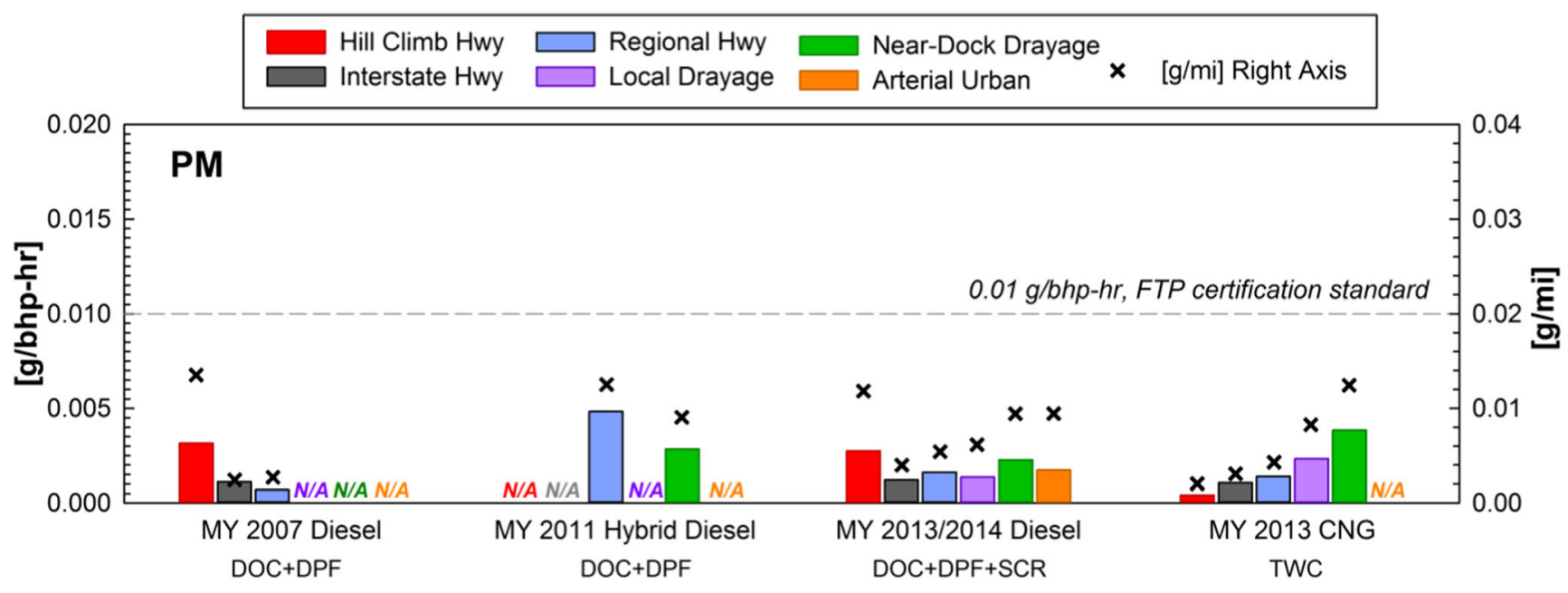

Fig. 9 Average PM emissions grouped by engine technology and route type 
times below the $0.01 \mathrm{~g} / \mathrm{bhp}-\mathrm{h}$ standard, which includes the infrequent regeneration adjustment factor (IRAF) that accounts for elevated PM emissions during DPF regeneration events. Data reported in Fig. 9 and Table 2 exclude trips with active DPF regeneration events to facilitate a comparison among groups without introducing bias into the comparison among routes. During trips without DPF regeneration events as shown in Fig. 9, emissions were at least two times below the certification standard (0.01 g PM/bhp-h) for the CNG and hybrid diesel, and at least three times below the certification standard for all conventional diesel vehicles.

These margins were slightly smaller when considering the periodic occurrence of active DPF regeneration events but clearly demonstrate the efficacy of the wall-flow DPF as a PM control strategy. Three vehicles underwent active DPF regenerations during the study; Vehicle 1 had two 20-min events ( $2.2 \%$ of total test time), Vehicle 6 had five $15-\mathrm{min}$ events ( $10.3 \%$ of total test time), Vehicle 7 had one $60-\mathrm{min}$ event (5.2\% of total test time). Without these exclusions, PM emissions would have been 2.3, 1.3, and 4.1 times higher per mile averaged over all trips made for Vehicles 1, 6, and 7, respectively. Still, the average brake-specific emissions from these vehicles including trips with active DPF regeneration events were still at least two times below the certification standard. Additionally and importantly, no active DPF regeneration events were observed for Vehicles 2, 4, and 5, which were all certified to the $0.01 \mathrm{~g} / \mathrm{bhp}-\mathrm{h} \mathrm{PM}$ and at least a $0.31 \mathrm{~g} /$ bhp-h NOx standard. Consistent with the findings from the 16-h engine dynamometer cycles conducted in the ACES II study where no active DPF regenerations were reported [29], in this on-road testing, active DPF regeneration did not occur for over $25-50 \mathrm{~h}$ of driving per vehicle during the valid tests in the study. Only one of the four SCR diesel vehicles (OEM 4, Vehicle 7) underwent active DPF regeneration; three of SCR diesel vehicles did not undergo active DPF regeneration (OEMS 1, 2, and 3).

Data in Fig. 9 show that PM emissions from diesel vehicles did not exhibit dramatic trends among routes. The MY 2011 diesel hybrid vehicle was associated with up to three times higher PM emission rates, on a brake-specific and per-mile basis compared to other diesel vehicles for the same routes, specifically the Regional Highway and Near-Dock Drayage routes. PM emissions from the $\mathrm{CNG}$ vehicle were generally higher on a brakespecific and per-mile basis for lower-load routes.

\subsubsection{Trip-Average PM Emissions and EMFAC2014 Predictions}

Figure 10a, b shows that the MY 2007 diesel and MY 2011 hybrid diesel vehicles had increased PM emissions for some trips with higher average speed compared to some trips with lower speeds. Some of these were due to active DPF regeneration events (labeled), and others such as the Hill Climb Highway

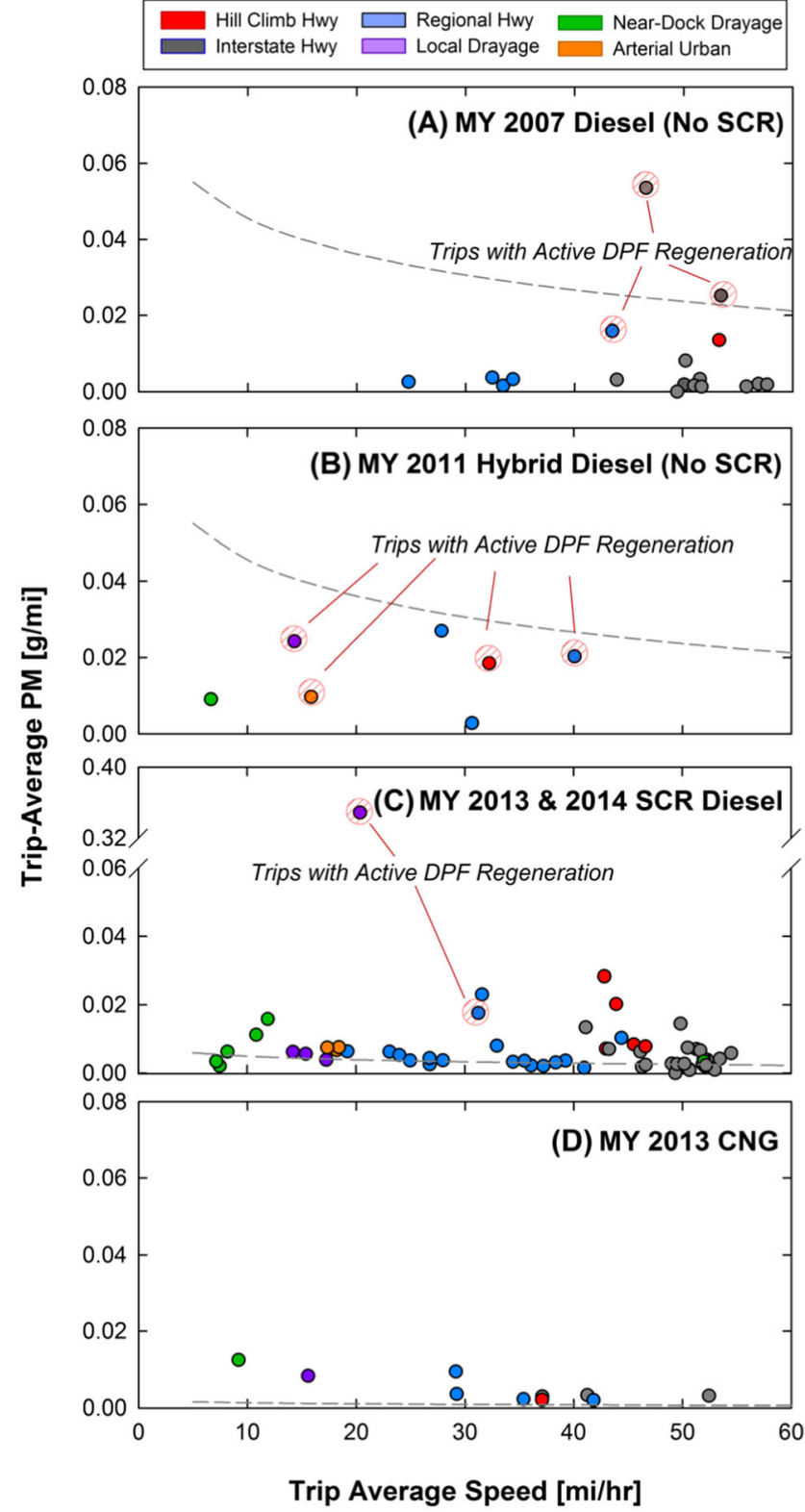

Fig. 10 Trip-average PM emissions (g/mi) versus trip-average speed by engine technology group. Each data point represents one unique vehicletrip typically lasting between 1 and $2 \mathrm{~h}$. Indicated MYs refer to those of the engine, which are assumed to be 1 year older than the vehicle MY emission rates used to develop the EMFAC model

route may have been due to higher exhaust and aftertreatment temperatures may have been conducive to passive regeneration of the more volatile PM species. The EMFAC prediction was slightly higher than the mode of measured data, which was likely because the ZMR used to represent these two engines from the model was based on MY 2008 vehicles in EMFAC that include approximately $3 \%$ MY 2006 engines, which are not originally equipped with DPFs, had dramatically higher PM emissions, and are proportionally averaged into the ZMR used.

Figure $10 \mathrm{c}, \mathrm{d}$ also shows scattered data - average speed is not a good predictor for PM emissions, but there is some 
downward trending of PM emissions with increasing tripaverage speed for the $\mathrm{CNG}$ vehicle as shown in routeaverage data presented in Fig. 9. The emission rate per time of PM may be more constant, and when converted into a distance-based emission factor, emissions are proportionally higher at lower speeds. Similar to the NOx emissions trends, trip-average PM emissions were frequently higher than EMFAC predictions for higher speeds (averages above $30 \mathrm{mi} / \mathrm{h}$ ), and especially trips made over the Hill Climb Highway Route. Note that the modeled predictions shown in the figure do not consider emission control DRs that are used in EMFAC, and if included here may result in better agreement between experimental and measured data. There was no evidence to suggest that the test vehicles were improperly maintained or exhibited emission control system deterioration. Nevertheless, when deriving a fleet-wide inventory, emission control system deterioration rates can dramatically influence emissions projections. For example, a recent evaluation found that approximately $7 \%$ of the DPFs operating on in-use vehicles in California between 2011 and 2014 accounted for up to $80 \%$ of the total diesel PM emissions from the DPF diesel fleet [12]. Overall, PM emissions from SCR diesel vehicles and $\mathrm{CNG}$ vehicle were low in this study, and during realworld operation, PM emissions are below the brake-specific certification standards.

\subsubsection{Speciation of PM Emissions by IC}

Figure 11 and Table 4 present results from ion chromatography (IC) analyses that were performed on selected test runs representing the MY 2007 diesel vehicle, and two SCR diesel vehicles (Vehicles 2 and 4), and the MY 2013 CNG vehicle (Vehicle 3). From these vehicles, active DPF regeneration only occurred while operating Vehicle 1, and these test runs were included in the analysis proportional to the frequency that they occurred during on-road testing. A total of 27 trips were selected, and additionally, six trip blank filters were transported with the samples and background levels were subtracted from field samples. Overall, sulfate and nitrate were the most abundant ionic species and contributors (respectively, up to 5.4 and $1.6 \mathrm{mg} / \mathrm{mi}$, and up to $30 \%$ of total mass), and additional elements detected in order of decreased overall abundance were sodium (up to $1.9 \mathrm{mg} / \mathrm{mi}$ or $15 \%$ ), calcium (up to $0.6 \mathrm{mg} / \mathrm{mi}$ or $4 \%$ ), potassium (up to $0.37 \mathrm{mg} / \mathrm{mi}$ or $3 \%$ ), ammonium (up to $0.19 \mathrm{mg} / \mathrm{mi} 2 \%$ ), magnesium (up to $0.10 \mathrm{mg} / \mathrm{mi}$ which is $<1 \%$ of total mass), and chloride (up to $0.18 \mathrm{mg} / \mathrm{mi}$, which is also $<1 \%$ of total mass). Exact trends varied primarily by engine technology, and to a lesser degree by route.

For the MY 2007 diesel engine, sulfate was the most abundant ionic species, contributing slightly more than one third of total filter mass for both Interstate and Regional Highway Cycles. The emission of sulfate was 7.6 times higher during trips that included an active DPF regeneration compared to test runs that did not; however, the reported emission rates are representative of actual frequency that it occurred during all valid emission tests. Sodium $(0.76 \mathrm{mg} / \mathrm{mi}$ average $)$ and nitrate $(0.51 \mathrm{mg} / \mathrm{mi}$ average $)$ were both dominantly present in emissions as well. The mass fraction of other components not detected by IC (e.g. organic carbon, elemental carbon, or hydronium ions $\left(\mathrm{H}^{+}\right)$) was approximately one third for Interstate Highway trips and one fifth for Regional Highway trips.

Nearly absent in the MY 2013 and 2014 SCR diesel engine exhaust was sulfate that accounted for less than $5 \%$ of total mass for any route. The presence of sulfate is due to catalytic conversion of $\mathrm{SO}_{2}$ to $\mathrm{SO}_{3}$ and combination with water to form sulfuric acid [35]; the aftertreatment temperatures may have remained below the reaction threshold as Vehicles 2 and 4 did not undergo active DPF regeneration, which typically increases aftertreatment temperature to above $550{ }^{\circ} \mathrm{C}$. The mass fraction of other components not detected by IC varied considerably by route type (approximately $90 \%$ for the Regional Highway route, and approximately $25 \%$ for the Near-Dock Drayage route). Nitrate dominated ionic fractions at both high speed (Interstate routes, $22 \%$ ) and low speed (Near-Dock Drayage route, $29 \%$ ). Particle-phase nitrate is likely due to the urea used to reduce NOx emissions in SCR systems. The second-most abundant species was sodium, which also was more dominant in the low-speed cycles, for example the NearDock Drayage Route $(0.43$ of $14.3 \mathrm{mg} / \mathrm{mi})$, the Local Drayage Route $(1.27$ of $4.15 \mathrm{mg} / \mathrm{mi})$, and Regional Highway routes (0.61 of $3.88 \mathrm{mg} / \mathrm{mi})$.

The ionic composition of PM emitted from the MY 2013 CNG vehicle was the lowest (17\%) on a percentage and total emissions basis. In contrast to a previous study that reported that the majority of PM mass was due to fuel and oil additive species such as magnesium $(\mathrm{Mg})$ and calcium $(\mathrm{Ca})$ [36], these accounted for small fractions of total PM $(<5 \%)$ in this evaluation. Sodium and sulfate were still the dominant species emitted from the CNG engine, and except for sodium during the Near-Dock Drayage route $(1.89$ of $12.4 \mathrm{mg} / \mathrm{mi})$, they remained relatively constant among routes. Ammonia emissions were observed from the $\mathrm{CNG}$ vehicle as expected from the water-gas shift reaction with $\mathrm{CO}$ and water over the TWC [37]; however, no formation of ammonium nitrate or other species was observed in the particulate phase as was observed from the SCR systems of diesel vehicles. Overall, PM emissions from this 12-L MY 2013 CNG engine with low mileage (11,142 mi, Table 1) appear to be relatively free from lube oil or engine additive species.

Sodium $(\mathrm{Na})$ was also detected in PM samples for the two diesel vehicle groups at approximately the same mass-based emission rates (0.41 for MY 2007 diesel vehicle, and $0.76 \mathrm{mg}$ / mi for the MY 2013 and 2014 SCR diesel vehicles) as for the CNG vehicle $(0.42 \mathrm{mg} / \mathrm{mi})$. The emission factors for sodium were about a factor of ten higher than those previously 


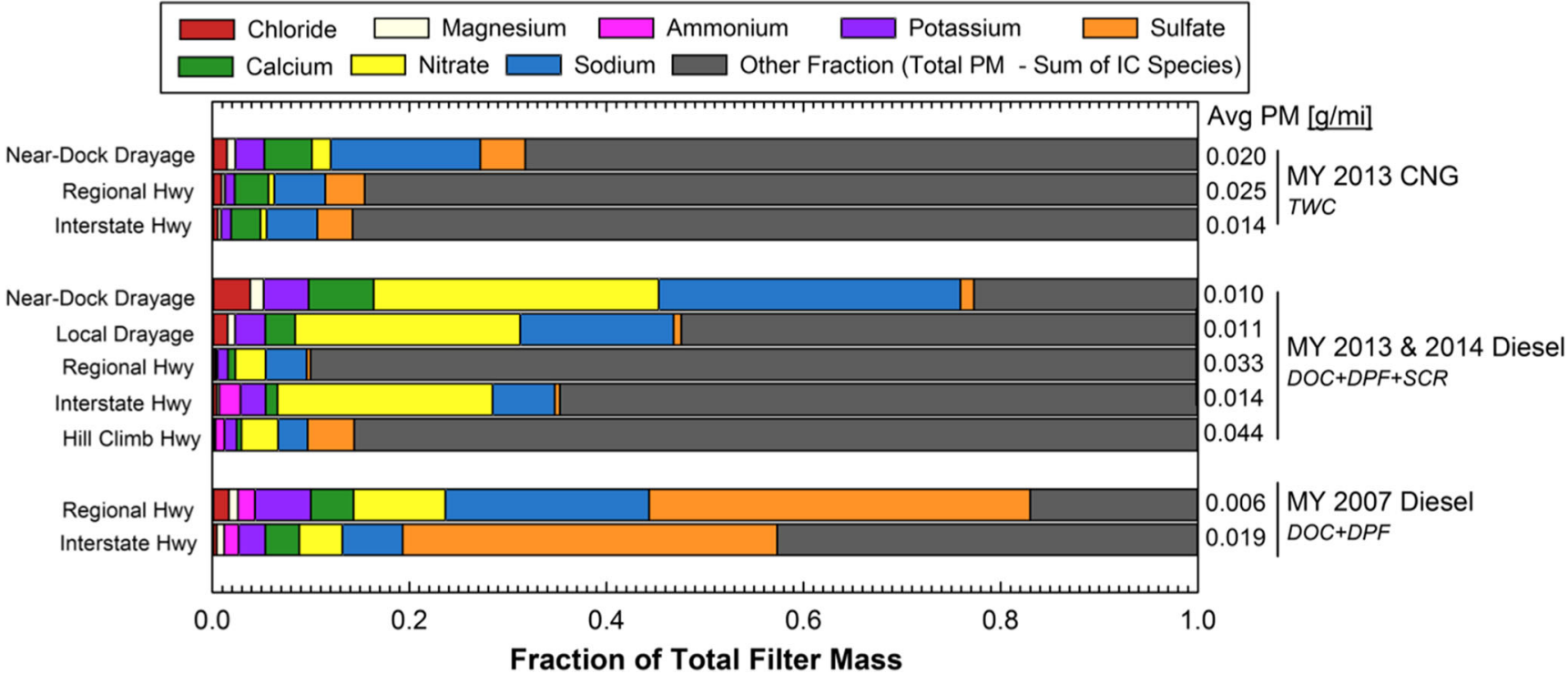

Fig. 11 Average ion speciation masses for 22 selected test runs over most route types. Other Fraction mass is the difference between total PM mass and the sum of all ionic masses detected using the IC methodology. This could be a combination of organic carbon, elemental carbon, or other ionic species such as hydronium $\left(\mathrm{H}^{+}\right)$

may be due to removal from ceramic core materials used in catalyzed flow-through or wall-flow aftertreatment systems. The mass of sodium likely did not originate from the fuel or lube oil as it is typically found at substantially lower concentrations than lube oil additives such as magnesium and calcium, both of which were only detected at low concentrations by IC analysis.

Table 4 Speciation of selected test runs using ion chromatography (IC) reported in milligrams per mile

\begin{tabular}{|c|c|c|c|c|c|c|c|c|c|c|}
\hline & $\begin{array}{l}\text { Total } \\
(\mathrm{mg} / \mathrm{mi})\end{array}$ & $\begin{array}{l}\text { Other } \\
(\mathrm{mg} / \mathrm{mi})\end{array}$ & $\begin{array}{l}\text { Sulfate } \\
(\mathrm{mg} / \mathrm{mi})\end{array}$ & $\begin{array}{l}\text { Sodium } \\
(\mathrm{mg} / \mathrm{mi})\end{array}$ & $\begin{array}{l}\text { Nitrate } \\
(\mathrm{mg} / \mathrm{mi})\end{array}$ & $\begin{array}{l}\text { Calcium } \\
(\mathrm{mg} / \mathrm{mi})\end{array}$ & $\begin{array}{l}\text { Potassium } \\
(\mathrm{mg} / \mathrm{mi})\end{array}$ & $\begin{array}{l}\text { Ammonium } \\
(\mathrm{mg} / \mathrm{mi})\end{array}$ & $\begin{array}{l}\text { Magnesium } \\
(\mathrm{mg} / \mathrm{mi})\end{array}$ & $\begin{array}{l}\text { Chloride } \\
\text { (mg/mi) }\end{array}$ \\
\hline \multicolumn{11}{|c|}{ MY 2007 Std. Diesel (DOC + DPF)—Vehicle 1} \\
\hline Average & 11.08 & 4.59 & 4.21 & 0.76 & 0.51 & 0.39 & 0.32 & 0.17 & 0.08 & 0.05 \\
\hline Interstate & 12.55 & 5.36 & 4.77 & 0.77 & 0.55 & 0.43 & 0.34 & 0.19 & 0.09 & 0.05 \\
\hline Regional & 3.71 & 0.63 & 1.43 & 0.77 & 0.35 & 0.16 & 0.21 & 0.07 & 0.03 & 0.06 \\
\hline \multicolumn{11}{|c|}{ MY 2010 Std. Diesel (DOC+DPF+SCR) -MY 2013 and MY 2014 engines - Vehicles 2 and 4} \\
\hline Average & 8.43 & 6.87 & 0.17 & 0.41 & 0.66 & 0.08 & 0.13 & 0.06 & 0.01 & 0.03 \\
\hline Hill Climb & 7.17 & 4.64 & 0.04 & 0.45 & 1.56 & 0.09 & 0.18 & 0.16 & 0.02 & 0.03 \\
\hline Interstate & 9.72 & 8.75 & 0.04 & 0.40 & 0.30 & 0.07 & 0.11 & 0.00 & 0.01 & 0.03 \\
\hline Regional & 3.88 & 2.04 & 0.03 & 0.61 & 0.89 & 0.12 & 0.12 & 0.00 & 0.03 & 0.06 \\
\hline Local & 4.15 & 0.94 & 0.06 & 1.27 & 1.20 & 0.27 & 0.19 & 0.00 & 0.06 & 0.16 \\
\hline Near-Dock & 14.29 & 12.23 & 0.67 & 0.43 & 0.53 & 0.07 & 0.18 & 0.13 & 0.01 & 0.03 \\
\hline \multicolumn{11}{|c|}{ MY 2010 Std. CNG (TWC) - MY 2013 engine - Vehicle 3} \\
\hline Average & 6.83 & 5.69 & 0.27 & 0.42 & 0.05 & 0.24 & 0.08 & 0.00 & 0.03 & 0.06 \\
\hline Interstate & 3.24 & 2.78 & 0.12 & 0.17 & 0.02 & 0.10 & 0.03 & 0.00 & 0.01 & 0.02 \\
\hline Regional & 5.81 & 4.91 & 0.23 & 0.30 & 0.04 & 0.20 & 0.06 & 0.00 & 0.02 & 0.05 \\
\hline Near Dock & 12.44 & 8.49 & 0.57 & 1.89 & 0.24 & 0.60 & 0.37 & 0.00 & 0.10 & 0.18 \\
\hline
\end{tabular}

No exclusions were performed for active DPF regeneration events. Other mass is the difference between total PM mass and the sum of all ionic masses detected using the IC methodology. This could be a combination of organic carbon, elemental carbon, or other ionic species such as hydronium $\left(\mathrm{H}^{+}\right)$ 


\section{Conclusions}

This study presents an overview of a recent on-road HD vehicle measurement program that measured criteria pollutants, GHGs, and other metrics from seven vehicles that are compliant with the $0.01 \mathrm{~g} / \mathrm{bhp}-\mathrm{h} \mathrm{PM}$ and $2.3,0.31$, or $0.2 \mathrm{~g} / \mathrm{bhp}-\mathrm{h}$ NOx standards. This paper presents criteria pollutant emissions, and results show that calculated brake-specific emissions are below relevant certification limits during realworld operation along major freight corridors in California. One exception was NOx, which exceeded brake-specific certification limits during lower-speed driving routes. On-road control of NOx emissions varies widely by engine manufacturers even when certified to the same emission standard. Furthermore, the extent of NOx control for each engine over different routes was relatively consistent among OEMs, and the certification NOx value was a poor predictor of relative on-road performance of the four MY 2013 and 2014 SCR diesel vehicles evaluated. Measured real-world criteria pollutant emissions generally agreed with the trends of emissions predicted by the current mobile source emissions model, EMFAC2014, which is used for air quality planning and regulatory assessment in California. As new emission control strategies and advanced vehicle technologies emerge and penetrate the market, continued real-world emissions testing will be critical for understanding and controlling the emissions from HD vehicles.

Acknowledgments The authors thank all the individuals who assisted during the project planning and testing; these individuals include Donald Chernich, Mark Burnitzki, Wayne Sobieralski, Robert Ianni, John Karim, Jesse Tu, Tung Tran, and Tony Nassar. The authors extend an additional thank you to the test vehicle drivers, Jason England and Jason Rowe, for their tireless hours on the road. The authors acknowledge Shiou-Mei Huang, M.-C. Oliver Chang, and Paul Rieger for their contributions to ion chromatography analysis. Finally, the authors thank Sam Pournazeri, Jeremy Smith, Christopher Ruehl, William Robertson, and Michael Benjamin for their review and input in developing this manuscript.

The statements and opinions expressed in this paper are solely the authors' and do not represent the official position of ARB. The mention of trade names, products, and organizations does not constitute endorsement or recommendation for use. ARB is a Department of the California Environmental Protection Agency. ARB's mission is to promote and protect public health, welfare, and ecological resources through effective reduction of air pollutants while recognizing and considering effects on the economy. ARB oversees all air pollution control efforts in California to attain and maintain health-based air quality standards.

Compliance with ethical standards The authors declare that they have no competing interests.

\section{References}

1. Touloumi, G., Katsouyanni, K., Zmirou, D., Schwartz, J., Spix, C., Ponce de Leon, A., Tobias, A., Quennel, P., Rabczenko, D., Bacharova, L., Bisanti, L., Vonk, J.M., Ponka, A.: Short-term effects of ambient oxidant exposure on mortality: a combined analysis within the APHEA Project. Am. J. Epidemiol. 146(2), 177185 (1997)

2. Lippmann, M.: HEALTH EFFECTS OF OZONE A Critical Review. JAPCA 39(5), 672-695 (1989)

3. Pope, C.A., Dockery, D.W.: Health effects of fine particulate air pollution: lines that connect. J. Air Waste Manage. Assoc. 56(6), 709-742 (2006)

4. Brook, R.D., Rajagopalan, S., Pope, C.A., Brook, J.R., Bhatnagar, A., Diez-Roux, A.V., Holguin, F., Hong, Y., Luepker, R.V., Mittleman, M.A.: Particulate matter air pollution and cardiovascular disease an update to the scientific statement from the American heart association. Circulation 121(21), 2331-2378 (2010)

5. CARB: proposed identification of diesel exhaust as a toxic air contaminant (initial statement of reasons). Sacramento, CA (1998)

6. Lloyd, A.C., Cackette, T.A.: Diesel engines: environmental impact and control. J. Air Waste Manage. Assoc. 51(6), 809-847 (2001)

7. CARB: Staff Report: 8-Hour Ozone State Implementation Plan Emission Inventory Submittal. Sacramento, CA (2014)

8. CARB: Proposed 8-Hour Ozone State Implementation Plan Revisions and Technical Revisions to the PM2.5 State Implementation Plan Transportation Conformity Budgets for the South Coast and San Joaquin Valley Air Basins. (2011)

9. CARB: Staff Report: ARB Review of San Joaquin Valley PM2.5 State Implementation Plan. (2015)

10. CARB: Sustainable Freight, Pathways to Zero and Near-Zero Emissions. Sacramento, CA (2015)

11. Greenhouse Gas Emissions Standards and Fuel Efficiency Standards for Medium- and Heavy-Duty Engines and Vehicles, Final Rule. In CFR Parts 523, 534, and 535, U.S.EPA: United States of America, Vol. Federal Register, Volume 76, No. 179 (2011)

12. CARB: evaluation of particulate matter (PM) filters in on-road heavy-duty diesel applications. (2015)

13. CARB: mobile source strategy, discussion draft, October 2015, (2015)

14. CARB: vision for clean air: a framework for air quality and climate planning (2012)

15. CARB: Amendments to the Regulation to Reduce Emissions of Diesel Particulate Matter, Oxides of Nitrogen and Other Criteria Pollutants From In-Use On-Road Diesel-Fueled Vehicles. In Division 3: Air Resources Board, Chapter 1: Motor Vehicle Pollution Control Devices, California Air Resources Board. Sacramento, CA, (2011)

16. CARB: evaluation of particulate matter filters in on-road heavyduty diesel vehicle applications (2015)

17. CARB: Final Phase 1 Greenhouse Gas and Optional Low NOx Amendments to California Exhaust Emission Standards and Test Procedures for 2004 and Subsequent Model Year Heavy-Duty Otto-Cycle Engines and Vehicles, (2014)

18. Velders, G.J.M., Geilenkirchen, G.P., de Lange, R.: Higher than expected NOx emission from trucks may affect attainability of NO2 limit values in the Netherlands. Atmos. Environ. 45(18), 3025-3033 (2011)

19. Bishop, G.A., Schuchmann, B.G., Stedman, D.H.: Heavy-Duty Truck Emissions in the South Coast Air Basin of California. Environ. Sci. Technol. 47(16), 9523-9529 (2013)

20. Misra, C., Collins, J.F., Herner, J.D., Sax, T., Krishnamurthy, M., Sobieralski, W., Burntizki, M., Chernich, D.: In-Use NOx Emissions from Model Year 2010 and 2011 Heavy-Duty Diesel Engines Equipped with Aftertreatment Devices. Environ. Sci. Technol. 47(14), 7892-7898 (2013)

21. Quiros, D.C., Yoon, S., Dwyer, H.A., Collins, J.F., Zhu, Y., Huai, T.: Measuring particulate matter emissions during parked active diesel particulate filter regeneration of heavy-duty diesel trucks. J. Aerosol Sci. 73, 48-62 (2014) 
22. Dwyer, H., Quiros, D., Burnitzki, M., Riemersma, R., Chernich, D., Collins, J., Herner, J.: Ambient Emissions Measurements from Parked Regeneration of 2007 and 2010 Diesel Particulate Filters. SAE 2014-01-2353 (2014)

23. Sharp, C. A., Feist, M. D., Laroo, C. A., Spears, M. W: Determination of PEMS measurement allowances for gaseous emissions regulated under the heavy-duty diesel engine in-use testing program part 3-results and validation. SAE Technical Paper, (2009)

24. Johnson, K.C., Durbin, T.D., Cocker Iii, D.R., Miller, W.J., Bishnu, D.K., Maldonado, H., Moynahan, N., Ensfield, C., Laroo, C.A.: On-road comparison of a portable emission measurement system with a mobile reference laboratory for a heavy-duty diesel vehicle. Atmos. Environ. 43(18), 28772883 (2009)

25. Cocker, D.R., Shah, S.D., Johnson, K.C., Zhu, X., Miller, J.W., Norbeck, J.M.: Development and Application of a Mobile Laboratory for Measuring Emissions from Diesel Engines. 2. Sampling for Toxics and Particulate Matter. Environ. Sci. Technol. 38(24), 6809-6816 (2004)

26. Wang, W.G., Lyons, D.W., Clark, N.N., Gautam, M., Norton, P.M.: Emissions from Nine Heavy Trucks Fueled by Diesel and Biodiesel Blend without Engine Modification. Environ. Sci. Technol. 34(6), 933-939 (2000)

27. Kappanna, H., Besch, M., Thiruvengadam, A., Delgado, O., Cozzolini, A., Carder, D., Gautam, M., Hu, S., Huai, T., Ayala, A: Greenhouse Gas Emissions of MY 2010 Advanced Heavy Duty Diesel Engine Measured Over a Cross-Continental Trip of USA. SAE Technical Paper (2013)

28. CARB: procedure for the analysis of particualte anions and cations in motor vehicle exhaust by ion chromatography. (2015)

29. CRC: Final Report, Phase 2 of the Advanced Collaborative Emissions Study, Coordinating Research Council, Health Effects Institute (HEI). Alpharetta, GA, (2013)

30. Yoon, S., Collins, J., Thiruvengadam, A., Gautam, M., Herner, J., Ayala, A.: Criteria pollutant and greenhouse gas emissions from CNG transit buses equipped with three-way catalysts compared to lean-burn engines and oxidation catalyst technologies. J. Air Waste Manage. Assoc. 63(8), 926-933 (2013)
31. Thiruvengadam, A., Besch, M.C., Thiruvengadam, P., Pradhan, S., Carder, D., Kappanna, H., Gautam, M., Oshinuga, A., Hogo, H., Miyasato, M.: Emission Rates of Regulated Pollutants from Current Technology Heavy-Duty Diesel and Natural Gas Goods Movement Vehicles. Environ. Sci. Technol. 49(8), 5236-5244 (2015)

32. Federal Register: Control of Emissions of Air Pollution From New Motor Vehicles: In-Use Testing for Heavy-Duty Diesel Engines and Vehicles. In Federal Register: United States. 70, 34594-34626 (2005)

33. CARB: Executive Order for Cummins Engine Family GCEXH0540LBJ: 8.9-L Natural Gas Engine Certified to the Optional $0.02 \mathrm{~g} / \mathrm{bhp}-\mathrm{hr}$ Low NOx Standard. In (2016)

34. CARB: EMFAC2014 Volume III-Technical Documentation. May 12, 2015, (2015)

35. Herner, J.D., Hu, S., Robertson, W.H., Huai, T., Chang, M.C.O., Rieger, P., Ayala, A.: Effect of Advanced Aftertreatment for PM and NOx Reduction on Heavy-Duty Diesel Engine Ultrafine Particle Emissions. Environ. Sci. Technol. 45(6), 2413-2419 (2011)

36. Thiruvengadam, A., Besch, M.C., Yoon, S., Collins, J., Kappanna, H., Carder, D.K., Ayala, A., Herner, J., Gautam, M.: Characterization of Particulate Matter Emissions from a Current Technology Natural Gas Engine. Environ. Sci. Technol. 48(14), 8235-8242 (2014)

37. Livingston, C., Rieger, P., Winer, A.: Ammonia emissions from a representative in-use fleet of light and medium-duty vehicles in the California South Coast Air Basin. Atmos. Environ. 43(21), 3326$3333(2009)$

38. Ntziachristos, L., Ning, Z., Geller, M.D., Sheesley, R.J., Schauer, J.J., Sioutas, C.: Fine, ultrafine and nanoparticle trace element compositions near a major freeway with a high heavy-duty diesel fraction. Atmos. Environ. 41(27), 5684-5696 (2007)

39. Verma, V., Ning, Z., Cho, A.K., Schauer, J.J., Shafer, M.M., Sioutas, C.: Redox activity of urban quasi-ultrafine particles from primary and secondary sources. Atmos. Environ. 43(40), 6360 6368 (2009)

40. Lough, G.C., Schauer, J.J., Park, J.-S., Shafer, M.M., DeMinter, J.T., Weinstein, J.P.: Emissions of Metals Associated with Motor Vehicle Roadways. Environ. Sci. Technol. 39(3), 826-836 (2005) 